\title{
Antimicrobial photodynamic therapy for inactivation of biofilms formed by oral key pathogens
}

\author{
Fabian Cieplik ${ }^{1}$, Laura Tabenski ${ }^{1}$, Wolfgang Buchalla ${ }^{1}$ and Tim Maisch ${ }^{2}$ \\ ' Department of Operative Dentistry and Periodontology, University Medical Center Regensburg, Regensburg, Germany \\ ${ }^{2}$ Department of Dermatology, University Medical Center Regensburg, Regensburg, Germany
}

\author{
Edited by: \\ Helen Zgurskaya, University of \\ Oklahoma, USA \\ Reviewed by: \\ George Tegos, University of New \\ Mexico, USA \\ Ali Al-Ahmad, Universitätsklinikum \\ Freiburg, Germany \\ Michael T. Ashby, University of \\ Oklahoma, USA \\ *Correspondence: \\ Fabian Cieplik, DDS, Department of \\ Operative Dentistry and \\ Periodontology, University Medical \\ Center Regensburg, \\ Franz-Josef-Strauß-Allee 11, \\ 93053 Regensburg, Germany \\ e-mail: fabian.cieplik@ukr.de
}

With increasing numbers of antibiotic-resistant pathogens all over the world there is a pressing need for strategies that are capable of inactivating biofilm-state pathogens with less potential of developing resistances in pathogens. Antimicrobial strategies of that kind are especially needed in dentistry in order to avoid the usage of antibiotics for treatment of periodontal, endodontic or mucosal topical infections caused by bacterial or yeast biofilms. One possible option could be the antimicrobial photodynamic therapy (aPDT), whereby the lethal effect of aPDT is based on the principle that visible light activates a photosensitizer (PS), leading to the formation of reactive oxygen species, e.g., singlet oxygen, which induce phototoxicity immediately during illumination. Many compounds have been described as potential PS for aPDT against bacterial and yeast biofilms so far, but conflicting results have been reported. Therefore, the aim of the present review is to outline the actual state of the art regarding the potential of aPDT for inactivation of biofilms formed in vitro with a main focus on those formed by oral key pathogens and structured regarding the distinct types of PS.

Keywords: photodynamic, aPDT, antimicrobial, biofilm, oral, antibiotic resistance

\section{INTRODUCTION}

Infections caused by bacterial biofilms are an immediate problem for public health as-according to the National Institutes of Health (NIH) - biofilm-associated diseases can be accounted for $80 \%$ of all infections in humans (PA-07-288: Immunology of Biofilms). According to Rodney M. Donlan and J. William Costerton the current definition of the term "biofilm" is as follows:

\footnotetext{
"A biofilm is a microbially derived sessile community characterized by cells that are irreversibly attached to a substratum or interface or to each other, are embedded in a matrix of extracellular polymeric substances that they have produced, and exhibit an altered phenotype [as compared to planktonic cells] with respect to growth rate and gene transcription" (Donlan and Costerton, 2002)
}

It is well known that the properties of bacteria embedded in biofilms are very different from those of their planktonic counterparts. For example, Shani et al. revealed that the concentrations of amine fluoride and chlorhexidine, which were able to kill monospecies biofilms of Streptococcus sobrinus, were about 100 times greater than the concentrations that were necessary to eradicate planktonic cultures of the same organism (Shani et al., 2000). Likewise, Ceri et al. showed that for eradication of biofilms of Escherichia coli, Pseudomonas aeruginosa, and Staphylococcus aureus even up to 1000 times higher concentrations of a certain antibiotic were required for the antibiotic to be effective compared to planktonic cells (Ceri et al., 1999). The enhanced tolerance of microorganisms growing in biofilms against antimicrobials can be explained as follows:

Firstly, the biofilm matrix-also referred to as EPS (extracellular polymeric substance)—itself may slow drug-diffusion by its higher viscosity or can even act as a barrier (Mah and O'Toole, 2001; Stewart and Costerton, 2001). For example, EPS-molecules are able to react with antimicrobials via redox-processes, positively charged agents bind to negatively charged EPS-molecules and $\pi-\pi$-interactions of aromatic surfaces are possible, preventing penetration of the respective drug in deeper parts of the biofilm (Mah and O'Toole, 2001; Stewart and Costerton, 2001).

Secondly, gene expression is altered between sessile and planktonic cells. Shemesh et al. demonstrated by a comparative transcriptome analysis for Streptococcus mutans that approximately $12 \%$ of genes showed a significantly dissimilar expression pattern in sessile and planktonic cells (Shemesh et al., 2007). Welin and Svensäter showed that in comparison to planktonic cells protein expression is altered in matured 3 days old biofilms as well as during the initial stage of biofilm formation; hereby they found that the expression of proteins related to the carbohydrate catabolism was elevated during initial attachment, whereas in matured biofilms it was reduced (Svensäter et al., 2001; Welin et al., 2004). Likewise, Lo et al. showed for Porphyromonas gingivalis, a periodontal pathogen, that approximately $18 \%$ of its genome was expressed distinctly when the bacterium was grown as monospecies biofilm; hereby, mainly genes involved in DNA replication and energy production were downregulated whereas a number of genes encoding binding and transport proteins were upregulated (Lo et al., 2009). 
Furthermore, development of a biofilm leads to an enormous genetic diversity of its cells, which provides "insurance" for the cells for better adaption to abrupt alteration of environment conditions (Kolter and Greenberg, 2006). Boles et al. showed for Pseudomonas aeruginosa that biofilm-grown cells had varying colony morphologies when plated on agar, whereas planktonicgrown cells had not; analyzing these biofilm-grown variants revealed that they differed notably in their biofilm building and detachment properties, susceptibility to oxidative stress and other properties (Boles et al., 2004). Likewise, so-called persister cells are being formed, when bacteria grow as a biofilm. These are in a dormant, non-dividing state and provide tolerance toward antimicrobial agents. This tolerance might function by preventing target corruption by an antimicrobial due to blocking of the target (Lewis, 2007). In contrast, resistance means target modification by mutation or enzymatic changes, target substitution, destruction or modification of the antibiotic, emergence of efflux pumps or restricted permeability for antibiotics through cell walls (Lewis, 2007).

To date, resistances of bacteria against antibiotics (Rossolini and Mantengoli, 2008) and antimicrobials like chlorhexidine (CHX) (Yamamoto et al., 1988) and triclosan (Yazdankhah et al., 2006) are arising and there is a pressing need for development of new antimicrobial approaches to fight biofilm infections. In January 2009, Cesar A. Arias and Barbara E. Murray published an article in the New England Journal of Medicine, where they warned that bacteria might even become winners of evolution since several strains have already adapted toward antibiotic and antimicrobial treatment that they become more and more resistant to conventional therapies; thus, they announced that this will be a "clinical super-challenge in the 21 st century" fighting the spread of resistance (Arias and Murray, 2009).

With respect to the situation in the oral cavity, dentists also are often faced with the situation that they have to combat antibioticresistant bacteria in periodontal (Rams et al., 2014) or endodontic
(Al-Ahmad et al., 2014) infections. For this reason,-in addition to promoting an adequate and rationalized use of antimicrobials (Leung et al., 2011)—there is immediate and continual research in human and dental medicine for alternative methods with less potential of development of resistances in pathogens. Multi-target processes are needed in contrast to those of antibiotics, which act very specific toward one explicit target according the so-called key-hole principle (Alves et al., 2014).

One of the most promising approaches to overcome the aforementioned shortcomings is the antimicrobial Photodynamic Therapy (aPDT). Its antimicrobial effect is based on an oxidative burst upon illumination and relies on damage to cellular structures and biomolecules, therefore being an unspecific mechanism (Maisch et al., 2011). aPDT needs the presence of three components, (I) a per se non-toxic dye, the so-called photosensitizer (PS), (II) visible light of an appropriate wavelength, and (III) molecular oxygen. The absorption of light by the PS leads to a transition to its triplet state, whereupon there are two mechanisms of reaction to let the PS regain its ground state: In type I mechanism, charge is transferred to a substrate or to molecular oxygen generating reactive oxygen species like hydrogen peroxide and oxygen radicals like superoxide ions or free hydroxyl radicals. In type II mechanism, energy only-not charge-is transferred directly to molecular oxygen, whereby the highly reactive singlet oxygen $\left({ }^{1} \mathrm{O}_{2}\right)$ originates (Wainwright, 1998; Schweitzer and Schmidt, 2003) (see Figure 1). Hereby, the singlet oxygen quantum yield $\Phi_{\Delta}$ describes the fraction of type II mechanism (Maisch et al., 2007).

In general, a PS used for aPDT should show the following features in order to have a pronounced antimicrobial efficacy and low toxicity toward mammalian cells:

- High ${ }^{1} \mathrm{O}_{2}$ quantum yield $\Phi_{\Delta}$ (Maisch et al., 2007).

- High binding affinity for microorganisms (positively charged PS for good adherence to negatively charged bacterial cell walls) (Alves et al., 2009).

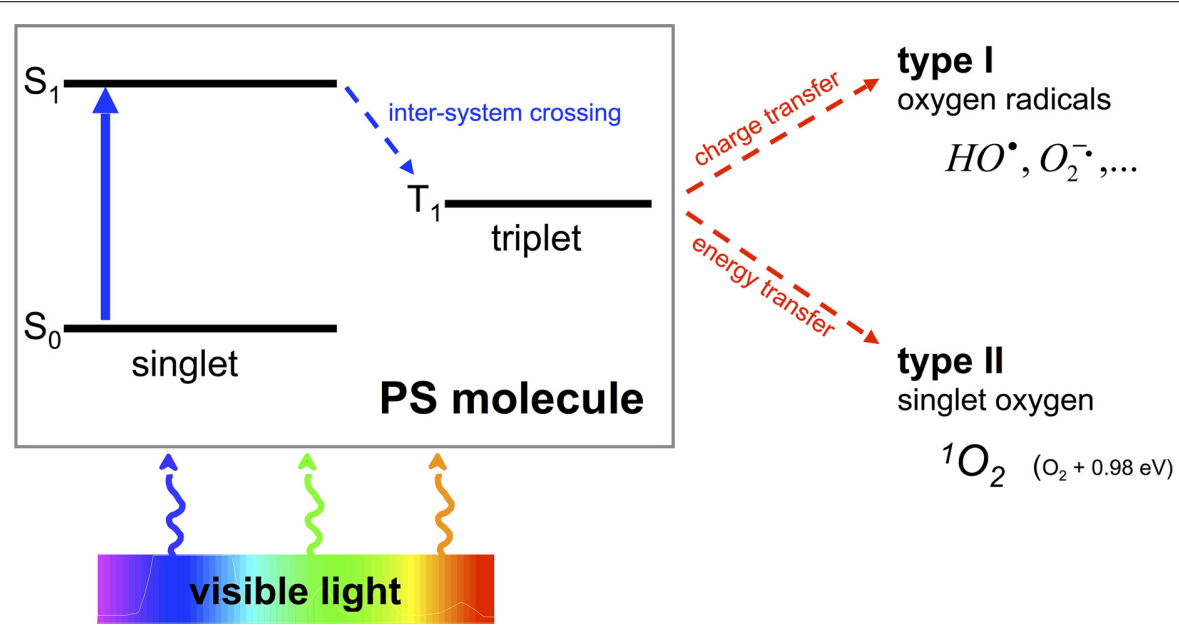

FIGURE 1 | Type I and type II processes of aPDT. Visible light of an appropriate wavelength is absorbed by the PS molecule by what the PS changes from its initial ground state $S_{0}$ to an energetically excited state $S_{1}$. Thereupon the PS is able to transition within the molecule from its singlet to its triplet state $T_{1}$ (inter-system crossing). This $T_{1}$ state is long-living compared to $\mathrm{S}_{1}$ so that charge (type I) or energy (type II) can be transferred to surrounding molecules such as oxygen with emergence of oxygen radicals (type I) or singlet oxygen (type II). 
- Low binding affinity for mammalian cells (Soukos and Goodson, 2011).

- Low chemical toxicity and mutagenicity (Soukos and Goodson, 2011).

The efficacy of many PS has already been evaluated for inactivation of biofilms grown in vitro: mainly there were used phenothiazinium dyes, such as Methylene Blue and Toluidine Blue, tetrapyrrolic macrocycles like porphyrins (e.g., TMPyP) or xanthene dyes like Erythrosine and Rose Bengal (RB). In addition, further chemical classes, e.g., functionalized fullerenes (Mizuno et al., 2011) or curcumin (Araújo et al., 2012, 2014) were presented. More recently a dye named SAPYR was introduced, which is based on a perinaphthenone structure (Cieplik et al., 2013b).

The aim of the present review is to outline the actual state of research concerning the effect of the photodynamic process for inactivation of bacterial and yeast biofilms in vitro with a main focus on aPDT against biofilms grown from oral key pathogens.

\section{aPDT AGAINST BIOFILMS IN VITRO}

In the following, only publications were included that investigated the efficacy of aPDT against bacterial and yeast biofilms grown in vitro. For ensuring better comparability, only studies were included, where the effect of aPDT was examined by performing colony forming unit (CFU) assays. CFU assay data is essential for evaluating a new antimicrobial approach, as the American Society of Microbiology (ASM) stated in 2010 that every new approach has to prove an efficacy of $3 \log _{10}$ reduction of CFU before being able to use the terms "antimicrobial" or "antibacterial."

\section{PHENOTHIAZINIUM DERIVATIVES}

The first phenothiazinium dyes were synthetized by the end of the 19th century in Germany in the context of a booming German textile industry. Hereby, Alizarin, which was developed in 1868 by Carl Graebe and Carl Liebermann, worked as some kind of precursor, when further research in the purpose of its manufacture and commercialization led to the development of new dyes (López-Muñoz et al., 2005). One of these new dyes was so-called "Methylene Blue (MB)"-the first phenothiazinium dye-whose synthesis protocol was patented by Heinrich Caro in the $1870 \mathrm{~s}$ (Caro, 1878).

Besides other applications, e.g., anti-malarial drugs or antipsychotic agents, phenothiazinium derivatives have been employed as PS due to their strong absorption in the red spectral region (ca. 600-680 nm) (Felgenträger et al., 2013). Phenothiazinium dyes are single positively charged and composed of a threering $\pi$-system with attached auxochromic side groups, whereby their singlet oxygen quantum yield $\Phi_{\Delta}$ is around 0.5 , thus acting according to type I and type II mechanisms (Wilkinson et al., 1993). Examples for phenothiazinium dyes, which have been tested for inactivation of biofilms in vitro, are foresaid MB [3,7-bis(dimethylamino)-phenothiazin-5-ium chloride] or Toluidine Blue [TBO; 3-amino-7-(dimethylamino)-2-methylphenothiazin-5-ium chloride] (see Figure 2).

Using MB, Fontana et al. investigated its effect on ex vivo polymicrobial biofilms cultivated from dental plaque samples taken from patients with chronic periodontitis. After a cultivation<smiles>CN(C)c1ccc2nc3ccc(N(C)C)cc3[s+]c2c1</smiles><smiles>Cc1cc2nc3ccc(N(C)C)cc3[s+]c2cc1N</smiles><smiles>Cc1cc2nc3cc(C)c(N)cc3[n+](-c3ccccc3Cl)c2cc1N</smiles>

FIGURE 2 | Phenothiazinium derivatives. Chemical structures of phenothiazinium derivatives: (A) Methylene Blue. (B) Toluidine Blue. (C) Safranine O.

period of 7 days, the biofilms were incubated with $\mathrm{MB}$ in concentrations of 25 or $50 \mu \mathrm{g} / \mathrm{ml}$ for $5 \mathrm{~min}$ and illuminated with a diode laser $(1 \mathrm{~W} ; 665 \mathrm{~nm})$ for another $5 \mathrm{~min}$, whereby a light dose of $30 \mathrm{~J} / \mathrm{cm}^{2}$ was applied, which resulted in a maximal inactivation rate of $32 \%$ CFU only. The authors concluded that this low susceptibility of complex dental biofilms toward aPDT may be overcome by novel delivery and targeting approaches (Fontana et al., 2009).

For testing the efficacy of $\mathrm{MB}$ on yeast biofilms, Rossoni et al. (2014) cultured biofilms of Candida albicans serotype A and B strains for $48 \mathrm{~h}$. After that period, biofilms were incubated with $\mathrm{MB}$ at a concentration of $300 \mu \mathrm{M}$ for $5 \mathrm{~min}$ and subsequently irradiated with a gallium-aluminum-arsenide (GaAlAs) laser ( $35 \mathrm{~mW} ; 660 \mathrm{~nm}$ ) for $285 \mathrm{~s}$, applying a light dose of $26.3 \mathrm{~J} / \mathrm{cm}^{2}$. This resulted in reductions of less than $1 \log _{10}(64 \%)$ for serotype A biofilms, whereas for serotype B biofilms there was a reduction of more than $2 \log _{10}$. The authors explained these distinct inactivation rates of Candida albicans serotype A and B biofilms by the differences in cell wall mannan structure between both serotypes. Furthermore, this difference in sensitivity to aPDT may be due to ultrastructural differences in EPS composition (Rossoni et al., 2014). However, in a comment to this study Mariusz Grinholc opposed that (i) only single reference strains of both serotypes and (ii) only one PS were tested, wherefore it may not be possible to conclude a general serotype-dependent sensitivity toward aPDT in cells of Candida albicans (Grinholc, 2014).

Employing TBO as a PS, the Brazilian group of Iriana C. J. Zanin conducted a number of studies (Zanin et al., 2005, 2006; Teixeira et al., 2012): In 2005 they examined its antimicrobial effect in combination with either a helium/neon $(\mathrm{HeNe})$ gas laser $(32 \mathrm{~mW} ; 632.8 \mathrm{~nm}$ ) or a light-emitting diode (LED; $32 \mathrm{~mW} ; 620$ $660 \mathrm{~nm}$ with a maximum at $638.8 \mathrm{~nm}$ ) on Streptococcus mutans 
biofilms grown on hydroxyapatite discs in a constant-depth film fermentor for 3, 7, or 10 days. After the respective culture period biofilms were incubated with $\mathrm{TBO}(100 \mathrm{mg} / \mathrm{l})$ for $5 \mathrm{~min}$ and afterwards irradiated for 5,15 , or $30 \mathrm{~min}$ with $\mathrm{HeNe}$ laser or LED light (light doses of 49,147 , or $294 \mathrm{~J} / \mathrm{cm}^{2}$ ). This resulted in reductions in viability of CFU of 2 to $5 \log _{10}$ steps depending on biofilm age, light source and irradiation period (Zanin et al., 2005). One year later, they tested the effect of TBO and LED light on monospecies biofilms of Streptococcus mutans, Streptococcus sobrinus, and Streptococcus sanguinis. Here, biofilms were cultivated for 5 days on enamel slabs. After incubation with TBO $(100 \mathrm{mg} / \mathrm{l})$ for $5 \mathrm{~min}$, biofilms were exposed to LED light (32 mW; 620-660 nm, maximum: $638.8 \mathrm{~nm}$ ) for $7 \mathrm{~min}$ (light dose: $\left.85.7 \mathrm{~J} / \mathrm{cm}^{2}\right)$. Results showed inactivation rates of approximately $1 \log _{10}$ step for Streptococcus mutans and Streptococcus sobrinus biofilms and more than $3 \log _{10}$ for Streptococcus sanguinis biofilms. The authors tried to explain these varying results by the ability of mutans streptococci like Streptococcus mutans and Streptococcus sobrinus to produce EPS to a greater extent than Streptococcus sanguinis, which is not among mutans streptococci (Zanin et al., 2006). In 2012, the same group published a combined in vitro and in situ report on the photodynamic effect of TBO: (i) biofilms of Streptococcus mutans were grown on hydroxylapatite discs for 5 days, (ii) volunteers wore intraoral devices with enamel slabs for 7 days under cariogenic challenge by dropping a sucrose solution 8 times per day. After the respective culture period biofilms were incubated with TBO $(100 \mathrm{mg} / \mathrm{l})$ for $5 \mathrm{~min}$ and irradiated with a LED light source $(40 \mathrm{~mW}, 620$ $660 \mathrm{~nm}$, maximum: $638.8 \mathrm{~nm}$ ) for $15 \mathrm{~min}$ (light dose $55 \mathrm{~J} / \mathrm{cm}^{2}$ ). For in vitro biofilms CFU were reduced by more than $5 \log _{10}$ steps after aPDT, whereas for in situ biofilms reduction was less than $1 \log _{10}$ step, when the numbers of CFU of Streptococcus mutans and total streptococci were examined. These distinct results were explained by the authors due to the thickness of the referring biofilms with in situ biofilms $(1000 \mu \mathrm{m})$ being approximately tenfold as thick as in vitro biofilms $(100 \mu \mathrm{m})$; therefore, they concluded that this problem could be solved e.g., by developing a PS being able to penetrate through the EPS (Teixeira et al., 2012).

As $\mathrm{MB}$ and $\mathrm{TBO}$ are designated to be potential efflux pump substrates in a variety of microbial species (Tegos and Hamblin, 2006; Prates et al., 2011) and due to the enhancing effect of efflux pump inhibitors on photodynamic inactivation of planktonic cells of Gram positives (Tegos et al., 2008), Kishen et al. (2010) tested the potentiating effect of an efflux pump inhibitor (verapamil hydrochloride) on aPDT with MB against Enterococcus faecalis monospecies biofilms. Hereby, 4 days old biofilms were incubated with MB or anionic RB (see below, Chapter Eosin Y, Erythrosine, Rose Bengal) as a control PS at concentrations of $100 \mu \mathrm{M}$ for $15 \mathrm{~min}$ in the dark and subsequently irradiated with a noncoherent light source with $30 \mathrm{~nm}$ bandpass filters (300$600 \mathrm{~mW}$; MB: $660 \pm 15 \mathrm{~nm}$; RB: $540 \pm 15 \mathrm{~nm}$ ), employing light doses from 10 to $40 \mathrm{~J} / \mathrm{cm}^{2}$. For $\mathrm{MB}$, there was a killing efficacy of more than $5 \log _{10}$ steps, which could even be enhanced slightly by an additional incubation with the efflux pump inhibitor. Employing RB exhibited only marginally worse results $\left(\approx 5 \log _{10}\right)$. However, CLSM analysis showed that aPDT with these PS had different effects on the Enterococcus faecalis biofilms: While aPDT with $\mathrm{RB}$ produced no substantial destruction of biofilm structure, aPDT with $\mathrm{MB}$ resulted in damage of biofilm structure to a greater extent (Kishen et al., 2010).

In a study investigating the efficacy of two commercially available systems for aPDT, Meire et al. (2012) treated $24 \mathrm{~h}$ old biofilms of Enterococcus faecalis either with $\mathrm{PAD}^{\mathrm{TM}}$ (Dentofex, Inverkeithing, UK) or $\mathrm{HELBO}^{\circledR} \quad\left(\mathrm{HELBO}^{\circledR}\right.$ Photodynamic Systems, Bredent medical, Senden, Germany) according to the recommendations of the manufacturers. For $\mathrm{PAD}^{\mathrm{TM}}$, biofilms were incubated for $2 \mathrm{~min}$ with $\mathrm{TBO}$ at a concentration of $12.7 \mathrm{mg} / \mathrm{l}$ and afterwards illuminated for $150 \mathrm{~s}$ with a soft diode laser $(100 \mathrm{~mW})$ emitting at $635 \mathrm{~nm}$. For HELBO ${ }^{\circledR}$, incubation of the Enterococcus faecalis biofilms was with $\mathrm{MB}(10 \mathrm{mg} / \mathrm{ml})$ for 3 min with a subsequent irradiation for $2 \mathrm{~min}$ with a soft laser (HELBO ${ }^{\circledR}$ Theralite Laser) obtaining a wavelength of $660 \mathrm{~nm}$ and an output-power of $75 \mathrm{~mW}$. Results showed a $2 \log _{10}$ step reduction for $\mathrm{HELBO}^{\circledR}$, whereas $\mathrm{PAD}^{\mathrm{TM}}$ exhibited only an inactivation rate of less than $1 \log _{10}$ step. When in addition the antibacterial efficacy of irradiation with Er:YAG (2940 nm; 50 or $100 \mathrm{~mJ} ; 15 \mathrm{~Hz}$; $40 \mathrm{~s})$ and Nd:YAG $(1064 \mathrm{~nm} ; 2 \mathrm{~W} ; 15 \mathrm{~Hz} ; 40 \mathrm{~s})$ lasers was tested, there was a $4 \log _{10}$ inactivation rate for Er:YAG treatment using $100 \mathrm{~mJ}$ pulses, whereas Er:YAG using $50 \mathrm{~mJ}$ pulses and Nd:YAG had no effect at all $\left(<1 \log _{10}\right)$. In contrast, treatment with $\mathrm{NaOCl}$ $(2.5 \% ; 1,5,10$, or $30 \mathrm{~min})$ showed reductions of more than $6 \log _{10}$ regardless which immersion periods were used. However, a prolonged action of $\mathrm{NaOCl}$ beyond the respective treatment periods cannot be ruled out, since no reagent was used for stopping its antimicrobial effect after the respective immersion period (Meire et al., 2012).

However, in addition to the above-mentioned batch-culture studies, phenothiazinium derivatives have also been examined in more applied models: Zand et al. (2014) used extracted human maxillary and mandibulary incisors, decoronated them and instrumented their root canals up to \#60 K-file. After an autoclavation process Enterococcus faecalis biofilms were formed in these root canals for 4,6 or 8 weeks. Subsequently, canals were incubated with TBO $(25 \mu \mathrm{g} / \mathrm{ml})$ for $5 \mathrm{~min}$ and irradiated with a $625 \mathrm{~nm}$ diode laser $\left(100 \mathrm{~mW}\right.$; light dose $\left.214.28 \mathrm{~J} / \mathrm{cm}^{2}\right)$ twice for $2.5 \mathrm{~min}$ intermitted by a $2.5 \mathrm{~min}$ break, applying a total of $2 \times 15 \mathrm{~J}$, which led to a complete elimination of Enterococcus faecalis below detection limit of the CFU assay (Zand et al., 2014).

In contrast, Fimple et al. (2008) investigated the photodynamic effects of $\mathrm{MB}$ on multispecies biofilms comprising Actinomyces israelii, Fusobacterium nucleatum, Prevotella intermedia, and Porphyromonas gingivalis in infected root canals of extracted human teeth. Teeth were decoronated, instrumented up to an apical file size of 0.465 , autoclaved and infected with the foresaid pathogens. After a culture period of 3 days canals were incubated with $\mathrm{MB}(25 \mu \mathrm{g} / \mathrm{ml})$ for $10 \mathrm{~min}$ and irradiated by means of a diode laser $(1 \mathrm{~W} ; 665 \mathrm{~nm})$ coupled to an optical fiber for $2.5 \mathrm{~min}$ followed by a $2.5 \mathrm{~min}$ break and a second light exposure of $2.5 \mathrm{~min}$, applying a total light dose of $30 \mathrm{~J} / \mathrm{cm}^{2}$. Results showed a CFU reduction by $80 \%$. The authors concluded that aPDT with MB could be an effective adjunct to conventional endodontic treatment, when the parameters get optimized (Fimple et al., 2008). 


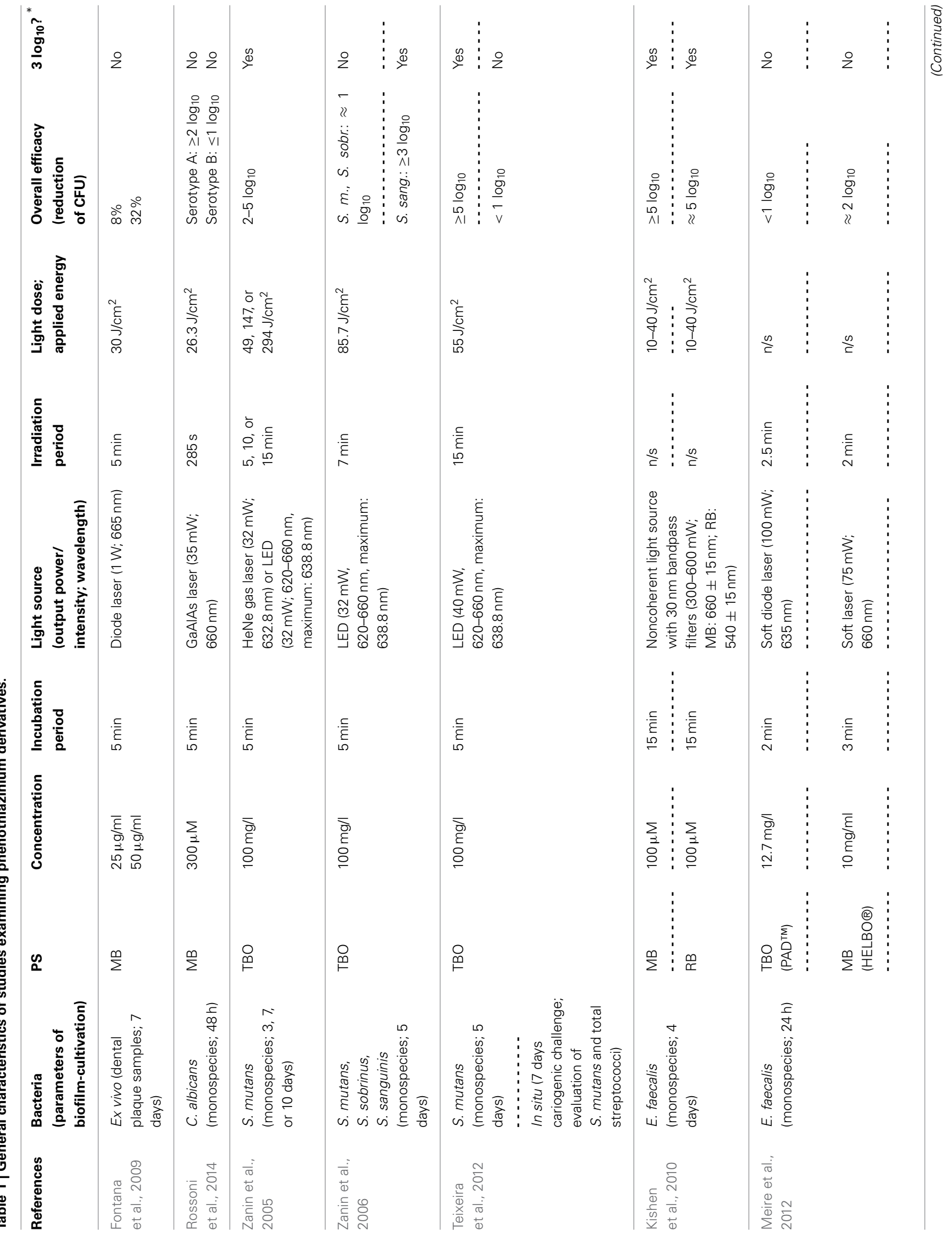




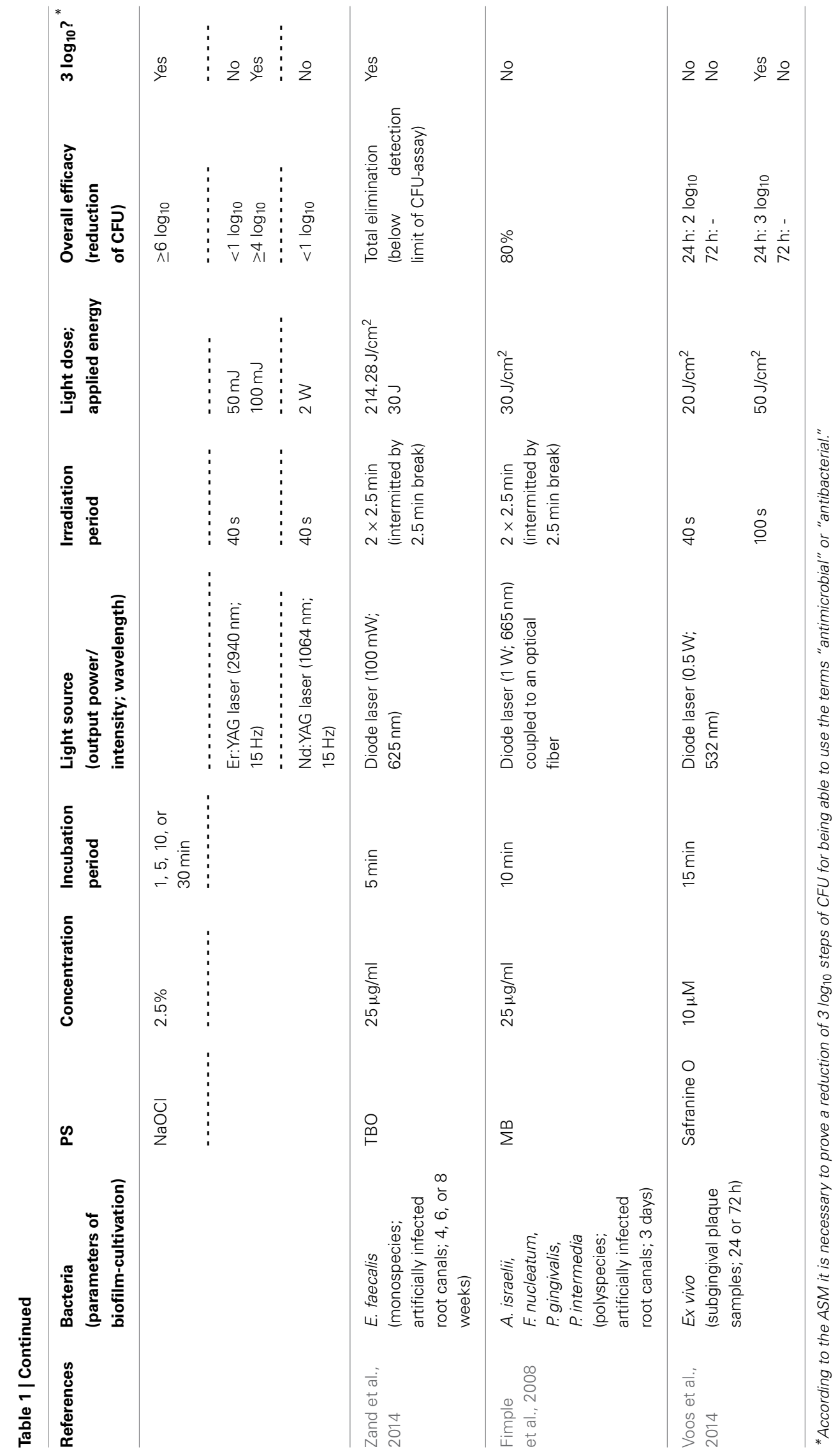


Up to date, phenothiazinium derivatives have to be regarded as the most studied PS in respect of inactivation of biofilms. Moreover, recently Voos et al. (2014) examined Safranine O (3,7-diamino-2,8-dimethyl-5-phenyl-phenazinium chloride), a structure analog to classical phenothiazinium dyes, where a nitrogen atom replaces the sulfur atom, which centers the delocalized electron system, for aPDT against biofilms. In this study, ex vivo biofilms were cultured from subgingival plaque samples for 24 or $72 \mathrm{~h}$. After the respective incubation period the biofilms were incubated with Safranine O $(10 \mu \mathrm{M})$ for $15 \mathrm{~min}$ followed by irradiation with a diode laser $(0.5 \mathrm{~W} ; 532 \mathrm{~nm})$ for 40 or $100 \mathrm{~s}$, applying light doses of 20 or $50 \mathrm{~J} / \mathrm{cm}^{2}$, respectively. In $24 \mathrm{~h}$ old biofilms there was a reduction of $2 \log _{10}$ steps with a light dose of $20 \mathrm{~J} / \mathrm{cm}^{2}$ and $3 \log _{10}$ steps with $50 \mathrm{~J} / \mathrm{cm}^{2}$, whereas treatment with CHX $(0.2 \% ; 3 \mathrm{~min})$ generated a reduction by $1 \log _{10}$ step only. In contrast, in $72 \mathrm{~h}$ old biofilms neither aPDT nor treatment with CHX led to any antibacterial effect (Voos et al., 2014) (Please find a summary of all studies described in this section in Table 1).

\section{PORPHYRINS, CHLORINS, AND PHTHALOCYANINES}

Porphyrins, chlorins, and phthalocyanines are structurally comparable heterocyclic macrocycles, whereby porphyrins and phthalocyanines are composed of four pyrrole subunits, while chlorins comprise three pyrrole cycles and one pyrroline (see Figure 3). Many of these compounds are naturally occurring. For example, one of the widest known porphyrins is heme, the pigment in erythrocytes, on which the red color of blood is based. Likewise, some bacterial species form porphyrins in their metabolism.

Oral bacteria that are able to synthetize for example blackpigmented species like Porphyromonas gingivalis and Prevotella spp. (Soukos et al., 2005; Lennon et al., 2006) or Aggregatibacter actinomycetemcomitans (Cieplik et al., 2013a). Consequently, it has been shown in vitro that these bacterial species can be inactivated by irradiation with light only, whereby it is a commonly accepted hypothesis that endogenous porphyrins among other substances may act as PS and lead to a lethal autophotosensitization process (König et al., 2000; Soukos et al., 2005; Lennon et al., 2006; Cieplik et al., 2013a). Porphyrins and chlorins have an intense absorption maximum at approximately $405 \mathrm{~nm}$, known as Soret band, and smaller peaks at wavelengths longer than $500 \mathrm{~nm}$ (Q bands) (Gouterman, 1961); their singlet oxygen quantum yields are in a range between 0.5 and 0.8 (Fernandez et al., 1997), thus acting predominantly according to type II mechanism.

There are some studies evaluating the efficacy of cationic PS being based on porphyrin or chlorin structures concerning the inactivation of biofilms. With respect to porphyrins, TMPyP [5,10,15,20-tetrakis(1-methyl-4-pyridinium)-porphyrin tetra-( $\mathrm{p}$-toluenesulfonate] - a fourfold positively charged derivative-has to be regarded as the most commonly used PS (Di Poto et al., 2009; Collins et al., 2010; Maisch et al., 2012; Cieplik et al., 2013b; Eichner et al., 2013; Gonzales et al., 2013). Di Poto et al. (2009) cultured biofilms from three distinct strains of Staphylococcus aureus for $24 \mathrm{~h}$, incubated them with TMPyP at a concentration of $10 \mu \mathrm{M}$ for $15 \mathrm{~min}$ and irradiated them with increasing doses of white light $\left(150-200 \mathrm{~J} / \mathrm{cm}^{2}\right)$ isolated from

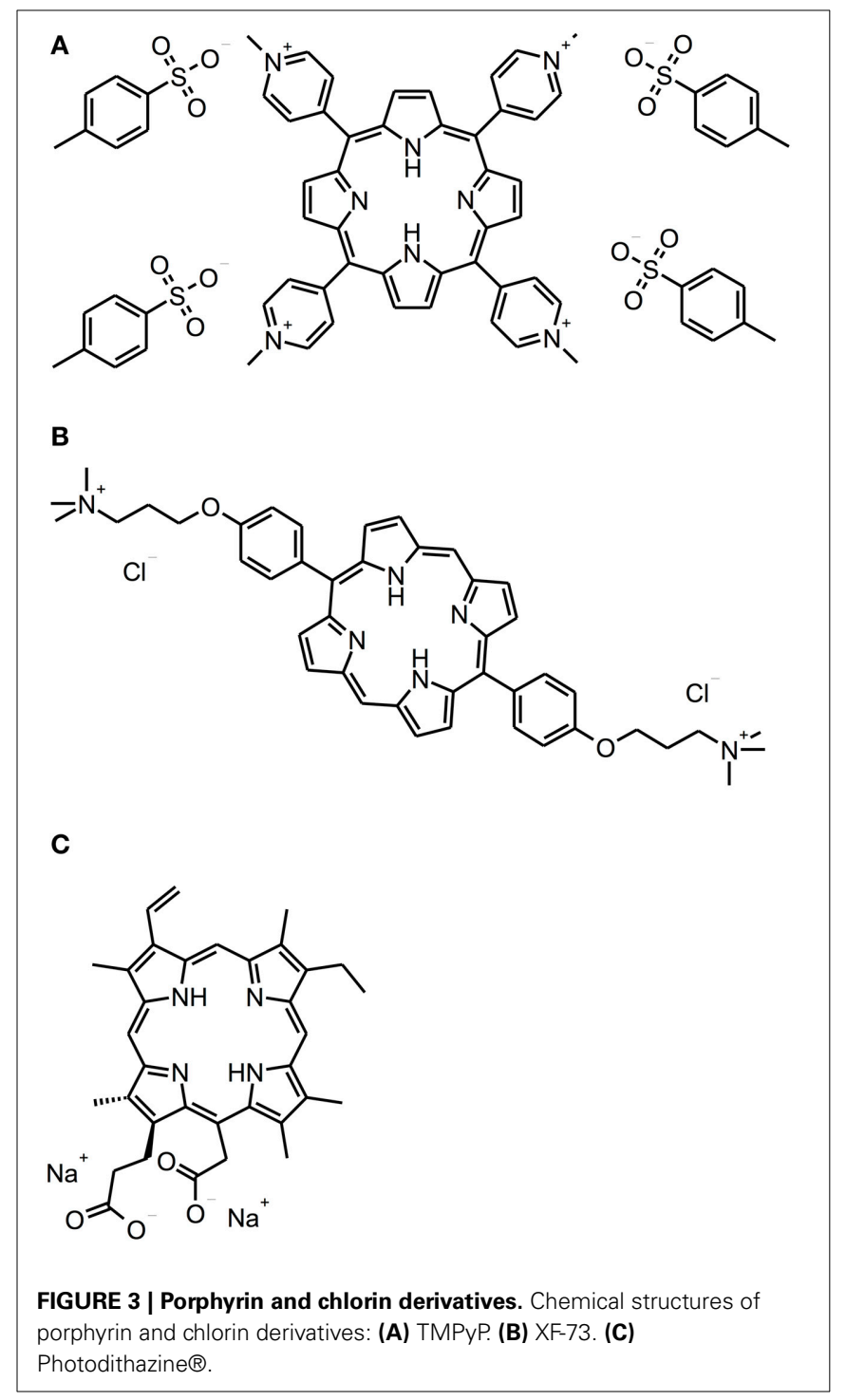

the emission of a tungsten lamp $\left(166 \mathrm{~mW} / \mathrm{cm}^{2} ; 400-800 \mathrm{~nm}\right)$, whereby this treatment exhibited a rate of bacteria killing of 1 to $2 \log _{10}$ steps at the highest light dose depending on the strain, which was tested. Hereby, CLSM analysis showed the presence of dead cells throughout the biofilm implying that there was no hindrance for the PS to diffuse into the biofilms; consequently, the authors suggested that the reduced susceptibility of biofilm bacteria compared to that, which was observed when planktonic bacteria were treated $\left(\geq 6 \log _{10}\right)$, may be due to differences in cell wall composition, growth rate or EPS-components hindering uptake of the PS through the cell walls. Furthermore, aPDT displayed a second anti-biofilm mechanism in this study leading to detachment of parts of the biofilm and therefore to a disruption of biofilm architecture (Di Poto et al., 2009).

Collins et al. (2010) tested the effect of aPDT with TMPyP on Pseudomonas aeruginosa biofilms, which were cultured for $24 \mathrm{~h}$ from a wild type or a mutant strain, respectively. After that period, $225 \mu \mathrm{M}$ TMPyP was applied, immediately followed by illumination with a mercury vapor lamp fitted with a colored glass filter 


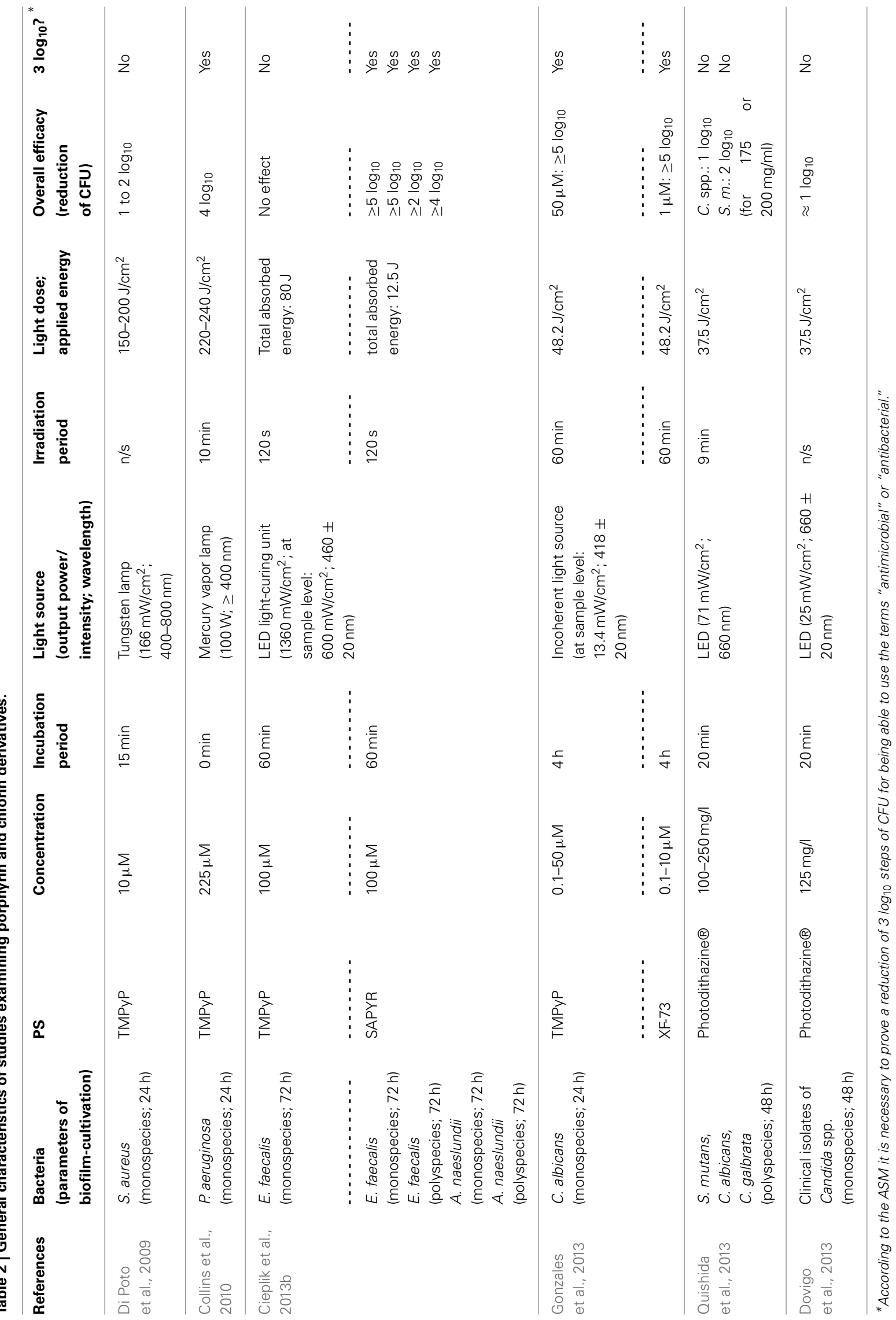


blocking wavelengths shorter than $400 \mathrm{~nm}(100 \mathrm{~W} ; \geq 400 \mathrm{~nm})$ for $10 \mathrm{~min}\left(220-240 \mathrm{~J} / \mathrm{cm}^{2}\right)$, which resulted in a pronounced inactivation rate of about $4 \log _{10}$ steps for both strains. In addition, CLSM analysis revealed that aPDT resulted in substantial disruption of wild-type biofilms, whereby TMPyP without irradiation did not have that effect (Collins et al., 2010).

In contrast, when our group used TMPyP for aPDT against monospecies biofilms of Enterococcus faecalis (as a control PS for evaluating the antibacterial efficacy of SAPYR, which will be discussed below) we found no reduction of CFU at all. In this study, after a cultivation period of $72 \mathrm{~h}$, biofilms were incubated with TMPyP $(100 \mu \mathrm{M})$ for $60 \mathrm{~min}$ and irradiated for $2 \mathrm{~min}$ with a LED light-curing unit for dental resins $\left(1360 \mathrm{~mW} / \mathrm{cm}^{2} ; 460 \pm\right.$ $20 \mathrm{~nm}$ ), whereby the intensity of light reaching the biofilms was $600 \mathrm{~mW} / \mathrm{cm}^{2}$. This inefficacy may be due to the large molecular structure of TMPyP, which may hinder the penetration of this PS throughout the EPS due to steric reasons. Furthermore, drug diffusion may also be delayed due to strong electrostatic interactions between fourfold positively charged TMPyP and negatively charged EPS-molecules. The emission of the LED light-curing unit was also not ideal for excitation of either SAPYR or TMPyP; nevertheless, this type of light source was chosen, as it is widely applied in dental practice (Cieplik et al., 2013b).

Pereira Gonzales et al. (2013) compared the antimicrobial efficacy of XF-73 [5,15-bis-[4-(3-trimethylammoniopropyloxy)phenyl]-porphyrin chloride]-a porphyrin derivative with two positive charges only-to that of TMPyP for inactivation of Candida albicans biofilms. These biofilms were cultured for $24 \mathrm{~h}$, incubated with increasing concentrations of PS for $4 \mathrm{~h}$ and illuminated with an incoherent light source $\left(13.4 \mathrm{~mW} / \mathrm{cm}^{2} ; 418 \pm\right.$ $20 \mathrm{~nm}$ ) for $60 \mathrm{~min}$, whereby a light dose of $48.2 \mathrm{~J} / \mathrm{cm}^{2}$ was applied. Results showed CFU reductions of more than $5 \log _{10}$ for concentrations of $1.0 \mu \mathrm{M}$ of XF-73 at least, whereas for TMPyP concentrations of $50 \mu \mathrm{M}$ were needed at the minimum for obtaining equal antimicrobial results. This was explained due to stronger electrostatic interactions of TMPyP with the EPS compared to XF-73 leading to a lower degree of diffusion of the PS into the biofilm (Gonzales et al., 2013).

Referring to chlorins, Photodithazine ${ }^{\circledR}$ is a commercially available cationic chlorin-e6 derivative with two absorption maxima at around $400 \mathrm{~nm}$ (Soret band) and $660 \mathrm{~nm}$ (slightly smaller peak, Q-band), which has been evaluated in two studies conducted by the group of Ana C. Pavarina (Dovigo et al., 2013; Quishida et al., 2013): Quishida et al. formed multispecies biofilms from Streptococcus mutans, Candida albicans and Candida galbrata for $48 \mathrm{~h}$; afterwards they were incubated with Photodithazine ${ }^{\circledR}$ at concentrations from 100 to $250 \mathrm{mg} / \mathrm{l}$ for $20 \mathrm{~min}$ and exposed to red light from a LED light source $\left(71 \mathrm{~mW} / \mathrm{cm}^{2} ; 660 \mathrm{~nm}\right)$ for $9 \mathrm{~min}$ (light dose $37.5 \mathrm{~J} / \mathrm{cm}^{2}$ ). At a PS-concentration of $200 \mathrm{mg} / \mathrm{ml}$ aPDT-treatment showed reductions of 1 or $2 \log _{10}$ steps for Candida spp. or Streptococcus mutans, respectively (Quishida et al., 2013). In another study from the same group, Dovigo et al. cultured monospecies biofilms of clinical isolates of Candida spp. according to the protocol outlined above. These were incubated with Photodithazine ${ }^{\circledR}(125 \mathrm{mg} / \mathrm{l})$ for $20 \mathrm{~min}$ and afterwards illuminated with a LED device $(25 \mathrm{~mW} / \mathrm{cm} 2 ; 660$ $\pm 20 \mathrm{~nm}$ ) applying a light dose of $37.5 \mathrm{~J} / \mathrm{cm}^{2}$. Results showed reductions of approximately $1 \log _{10}$ step (Dovigo et al., 2013). However, in both of these studies Photodithazine ${ }^{\circledR}$ was excited by red light at its minor absorption peak at $660 \mathrm{~nm}$ without this point being discussed by the authors. Consequently, irradiation with blue light at $400 \mathrm{~nm}$ may lead to better results (Dovigo et al., 2013; Quishida et al., 2013).

In contrast to porphyrins and chlorins, phthalocyanines are highly hydrophobic, which compromises their water solubility (Ribeiro et al., 2013b). Therefore, methods for solubilization of phthalocyanines are mandatory for applying these compounds as PS for aPDT, whereby one option is their entrapment in nanoemulsions. Ribeiro et al. evaluated chloro-aluminum phthalocyanine $(\mathrm{ClAlPc})$ encapsulated in cationic and anionic nanoemulsions (final concentration of ClAlPc in nanoemulsions: $31.8 \mu \mathrm{M}$ ) in two studies regarding its aPDT-efficacy on biofilms of Candida albicans (Ribeiro et al., 2013a,b). However, in these studies the antimicrobial efficacy was only examined by detecting metabolic cell activity with XTT reduction assay. Consequently, this data is not comparable to CFU-assay data, which is mandatory, since-according to the ASM-any novel approach has to accomplish a CFU reduction rate of more than 3 $\log _{10}$ in order to use the terms "antibacterial" or "antimicrobial" (Table 2).

\section{EOSIN Y, ERYTHROSINE, ROSE BENGAL}

Eosin Y, Erythrosine and Rose Bengal (RB) are anionic xanthene dyes derived from fluorescein. Hereby, Eosin $\mathrm{Y}$ and Erythrosine are red dyes resulting from the action of either bromine or iodine on fluorescein, whereas $\mathrm{RB}$ is a pink dye eventuating from a tetrachlorination of Erythrosine (see Figure 4). All these dyes show intense absorption bands in the green wavelength range (480-550 nm) (DeRosa and Crutchley, 2002); their singlet oxygen quantum yields are between 0.6 and 0.8 , therefore mainly acting according to type II mechanism (Wilkinson et al., 1993).

Employing Erythrosine (ERY; 2,4,5,7-tetraiodofluorescein) as a PS for aPDT, Wood et al. (2006) studied its effect on $200 \mu \mathrm{m}$ thick biofilms of Streptococcus mutans, which were grown for up to $288 \mathrm{~h}$ in a constant-depth film fermentor, and compared it to $\mathrm{MB}$ and Photofrin, a Porphyrin derivative. The biofilms were incubated with $22 \mu \mathrm{M}$ ERY, MB, or Photofrin for $15 \mathrm{~min}$ and exposed to white light from a tungsten filament lamp (ERY: $22.7 \mathrm{~mW} / \mathrm{cm}^{2}$ in the wavelength range $500-550 \mathrm{~nm} ; \mathrm{MB}$, Photofrin: $22.5 \mathrm{~mW} / \mathrm{cm}^{2}$ at $600-650 \mathrm{~nm}$ ) for $15 \mathrm{~min}$. Hereby, ERY-mediated aPDT resulted in a reduction of about $3 \log _{10}$ steps for $288 \mathrm{~h}$ old biofilms, whereas aPDT with $\mathrm{MB}$ and Photofrin showed only 2.6 or $1.1 \log _{10}$ steps inactivation, respectively. Contrary to expectations, $48 \mathrm{~h}$ old biofilms were less susceptible to aPDT, regardless which PS was used (ERY: $2.2 \log _{10}$; MB: $1.5 \log _{10}$; Photofrin: $\left.0.5 \log _{10}\right)$. The authors explained this as young biofilms may be more metabolically active, thus having more effective repair systems. Moreover, older biofilms may contain voids and channels through the EPS, allowing greater amount of penetration of the respective PS (Wood et al., 2006). However, negatively charged ERY being the most effective PS in this study is quite contradictory to the above-mentioned general opinion, how a "perfect" PS should be composed, as the positive charge of a PS appears to promote an electrostatic interaction 
<smiles></smiles>

B<smiles>O=C([O-])c1ccccc1-c1c2cc(I)c(=O)c(I)c-2oc2c(I)c([O-])c(I)cc12</smiles>

C<smiles>[NH3+]C(=O)c1c(Cl)c(Cl)c(Cl)c(Cl)c1-c1c2cc(I)c(=O)c(I)c-2oc2c(I)c([O-])c(I)cc12</smiles>

D<smiles>CC(C)(C)COC1C(O)CC(C)(C)CC(C)(C)C1NC(=O)c1c(Cl)c(Cl)c(Cl)c(Cl)c1-c1c2cc(I)c(=O)c(I)c-2oc2c(I)c([O-])c(I)cc12</smiles>

FIGURE 4 | Fluorescein derivatives. Chemical structures of fluorescein derivatives: (A) Eosin Y. (B) Erythrosine. (C) Rose Bengal. (D) Chitosan-conjugated Rose Bengal.

with negatively charged sites at the outer membrane of bacterial cells (Maisch et al., 2004). In contrast, anionic fluorescein derivatives like ERY or RB may be efficient though due to their high lipophilicity. In another study of the same group, Metcalf et al. (2006) investigated the effect of light-fractionation on aPDT with ERY on Streptococcus mutans biofilms formed under equal experimental parameters. ERY was used at $22 \mu \mathrm{M}$ with a $15 \mathrm{~min}$ incubation period, too. Biofilms were illuminated with the same tungsten filament lamp $\left(22.7 \mathrm{~mW} / \mathrm{cm}^{2} ; 500-550 \mathrm{~nm}\right)$, whereby a light dose of $6.75 \mathrm{~J} / \mathrm{cm}^{2}$ was applied for every $5 \mathrm{~min}$ of irradiation. Here, it was shown that aPDT with ERY can be potentiated by light fractionation: Streptococcus mutans could be inactivated by about $2 \log _{10}$ steps, when ERY was irradiated continuously for $5 \mathrm{~min}$, whereas rates of $3 \log _{10}$ and 3.7 $\log _{10}$ could be achieved, when there were either $5 \times 1$ min light pulses with $5 \mathrm{~min}$ recovery periods or $10 \times 30 \mathrm{~s}$ light pulses with 2 min recovery breaks between pulses. This was explained by the authors due to replenishment of target molecules such as oxygen for the PS during the dark periods (Metcalf et al., 2006).

In order to compare the photodynamic efficacy of ERY and RB (4,5,6,7-tetrachloro- $2^{\prime}, 4^{\prime}, 5^{\prime}, 7^{\prime}$-tetraiodofluorescein), Pereira et al. (2013) cultured biofilms of Streptococcus mutans and Streptococcus sanguinis for $48 \mathrm{~h}$ and incubated them with either with ERY or RB at concentrations of $5 \mu \mathrm{M}$ for $5 \mathrm{~min}$ followed by irradiation with a blue LED $(200 \mathrm{~mW} ; 455 \pm 20 \mathrm{~nm})$ for $180 \mathrm{~s}$ (light dose: $95 \mathrm{~J} / \mathrm{cm}^{2}$; applied energy: $36 \mathrm{~J}$ ). This treatment exhibited small effects of less than $1 \log _{10}$ for both species regardless of whether ERY or RB was used. However, it has to be considered that blue light from a $455 \mathrm{~nm}$ LED may not be optimal for excitation of ERY and RB with green light being more appropriate (Pereira et al., 2013). In a study from the same group, Freire et al. (2013) compared RB with Eosin Y (2,4,5,7tetrabromofluorescein) concerning their potency for inactivation of Candida albicans biofilms. After culturing these biofilms for $48 \mathrm{~h}$, treatment was done with $200 \mu \mathrm{M}$ RB or Eosin Y for $5 \mathrm{~min}$ as a pre-irradiation period and subsequent illumination with a green LED $\left(90 \mathrm{~mW} ; 532 \pm 10 \mathrm{~nm}\right.$ ) for $180 \mathrm{~s}$ (light dose: $42.63 \mathrm{~J} / \mathrm{cm}^{2}$; applied energy: $16.2 \mathrm{~J})$, which resulted in inactivation rates of 0.22 and $0.45 \log _{10}$ for RB and Eosin Y, respectively (Freire et al., 2013). In contrast to those results, Kishen et al. achieved a high killing efficacy of approximately $5 \log _{10}$ steps, when using RB against Enterococcus faecalis monospecies biofilms, as mentioned above (see Chapter Phenothiazinium Derivatives) (Kishen et al., 2010).

However, as cationic PS are needed for good antimicrobial photodynamic activity, the group of Annie Shrestha and Anil Kishen synthesized a polycationic chitosan-conjugated Rose Bengal (CSRB) for mounting a positive charge on anionic RB (Shrestha and Kishen, 2012; Shrestha et al., 2012). This conjugate was evaluated against Enterococcus faecalis and Pseudomonas aeruginosa biofilms, whereby its efficacy was compared to RB and MB. Biofilms were cultured for 7 days, incubated for $15 \mathrm{~min}$ with the respective PS at concentrations of $0.3 \mathrm{mg} / \mathrm{ml}$ (CSRB) or $10 \mu \mathrm{M}(\mathrm{RB}, \mathrm{MB})$ and irradiated by $540 \mathrm{~nm}$ (CSRB, $\mathrm{RB})$ or $660 \mathrm{~nm}$ (MB) fibers. Applying a light dose of $40 \mathrm{~J} / \mathrm{cm}^{2}$ resulted in inactivation rates of about $3 \log _{10}$ steps for $\mathrm{MB}$ in both biofilms, while for $\mathrm{RB}$ there were reductions of $3 \log _{10}$ steps in Pseudomonas aeruginosa biofilms and $4 \log _{10}$ steps in Enterococcus faecalis biofilms. In contrast, when using CSRB there was an inactivation of $9 \log _{10}$ steps of Pseudomonas aeruginosa and $5 \log _{10}$ steps of Enterococcus faecalis. The authors explained these strikingly better results of CSRB compared to anionic $\mathrm{RB}$ and cationic $\mathrm{MB}$ due to the greater ability of CSRB to adhere to bacterial cells and the synergistic antibacterial effects of chitosan and RB (Shrestha and Kishen, 2012) (Table 3). 


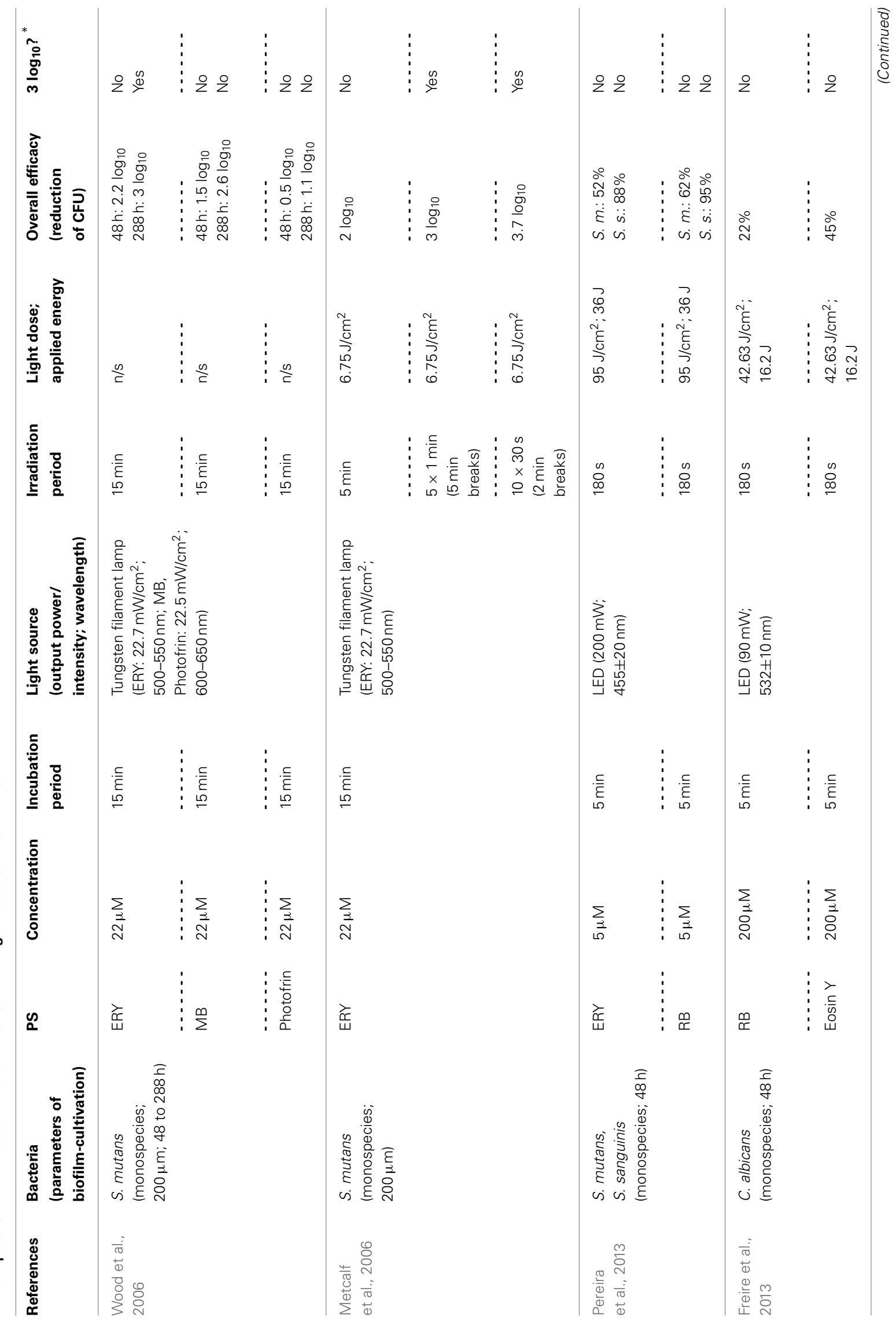




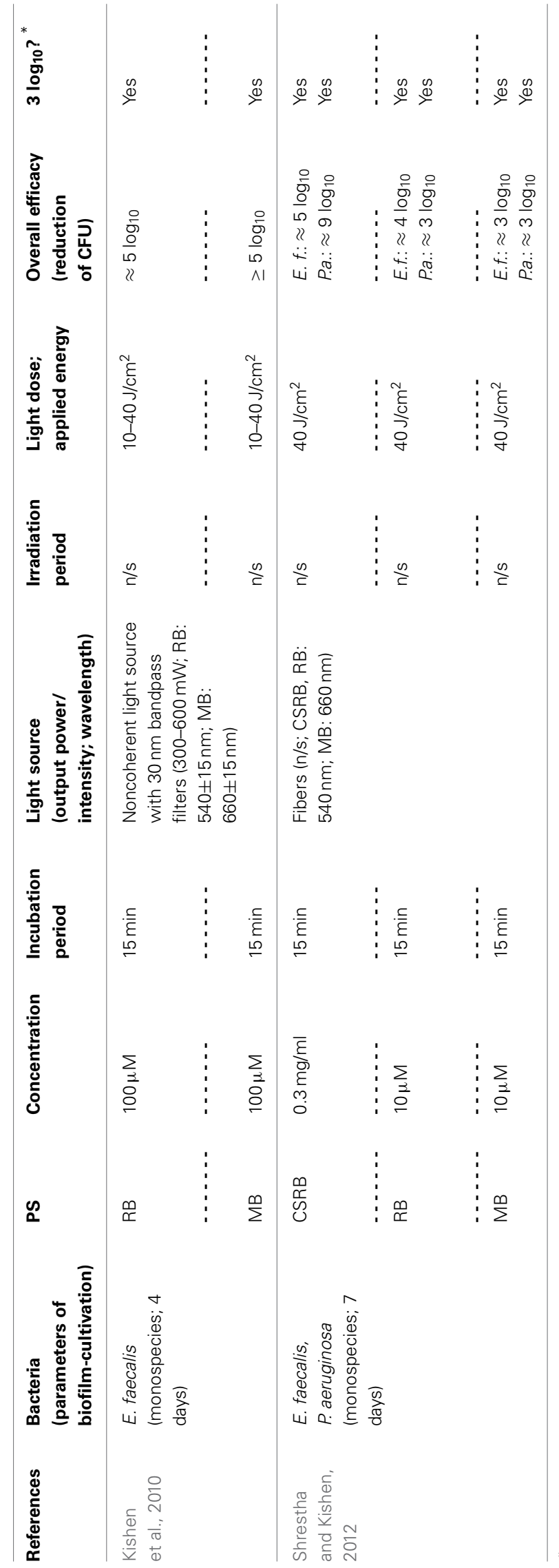

\section{CURCUMIN, PERINAPHTHENONE AND FULLERENE DERIVATIVES}

Recently, new classes of PS have been introduced as PS for aPDT: Curcumins, perinaphthenone derivatives and fullerenes (see Figure 5).

Curcumin [1E,6E-1,7-bis(4-hydroxy-3-methoxyphenyl)-1,6heptadiene-3,5-dione] is a naturally occurring intense-yellow dye, isolated from the rootstocks of the plant Curcuma longa, which has been used as medicine, spice and food-colorant for hundreds of years (Crivello and Bulut, 2005; Aggarwal et al., 2007). As its absorption spectrum is in the UV/blue wavelength range $(300-500 \mathrm{~nm}$ with a maximum at $430 \mathrm{~nm})$, it has been thought to be a feasible PS for aPDT (Araújo et al., 2012). However, curcumin is a nearly quantitative type I mechanism PS, whose photodynamic effect is due to hydrogen peroxide without generation of singlet oxygen (Dahl et al., 1989).

Araújo et al. (2014) evaluated the susceptibility of Streptococcus mutans and Lactobacillus acidophilus, either grown in multispecies biofilms or in artificial dentine carious lesions, toward aPDT with a curcumin-solution (consisting of $66.7 \%$ glucamin, $17.8 \%$ curcumin, $15.5 \%$ demethoxy and bisdemethoxy curcumin; concentration: 0.75 to $5 \mathrm{~g} / \mathrm{l})$. Biofilms were cultured for 7 days, exposed to the curcumin-solution for $5 \mathrm{~min}$ and irradiated for<smiles>COc1cc(/C=C/C(=O)CC(=O)/C=C/c2ccc(O)c(OC)c2)ccc1O</smiles>

B<smiles>O=C1C(S(=O)(=O)O)=Cc2cccc3cccc1c23</smiles>

C<smiles>O=C1C(C[n+]2ccccc2)=Cc2cccc3cccc1c23</smiles>

D

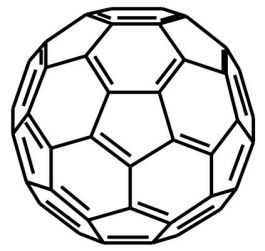

FIGURE 5 | Curcumin, perinaphthenone and fullerene derivatives. Chemical structures of curcumin, perinaphthenone and fullerene derivatives: (A) Curcumin. (B) PNS. (C) SAPYR. (D) Fullerene C60. 


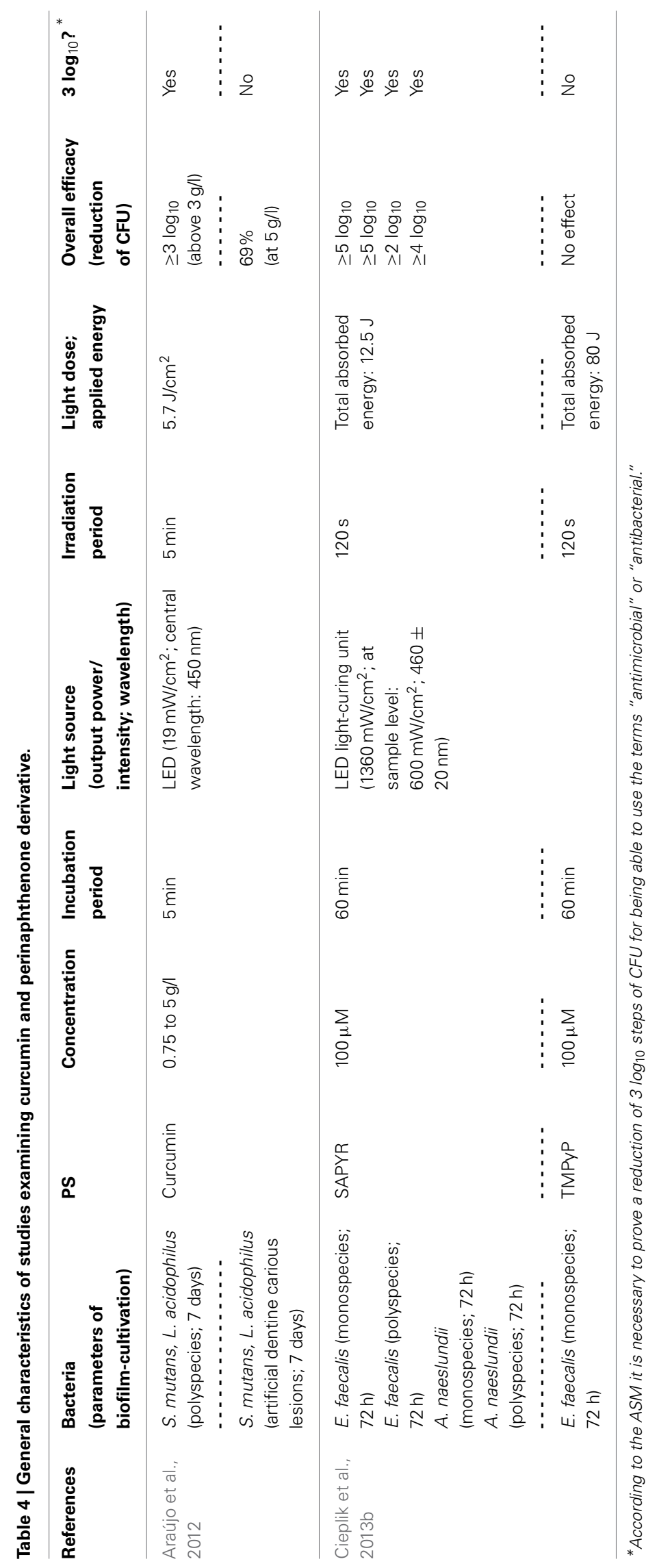


5 min with blue light derived from a LED (central wavelength: $450 \mathrm{~nm}$; light dose: $5.7 \mathrm{~J} / \mathrm{cm}^{2}$ ). With curcumin-concentrations above $3 \mathrm{~g} / \mathrm{l}$, CFU were reduced by more than $3 \log _{10}$ steps in the multispecies biofilms. However, when the dentine carious lesion was exposed to curcumin ( $5 \mathrm{~g} / \mathrm{l})$ with subsequent irradiation, there was only a small reduction of $69 \%$; this reduced effect on bacteria located in demineralized dentine was explained by the authors due to decreased penetration depth of the PS, diminished binding to bacterial cells or attenuated penetration of light (Araújo et al., 2014).

In contrast to curcumins, perinaphthenones are only slight yellowish and exhibit singlet oxygen quantum yields close to unity, therefore acting nearly exclusively according to type II mechanism. Consequently, PNS (1H-phenalen-1-one-2-sulfonic acid), which was the first derivative of perinaphthenone being employed as a PS (originally described by Nonell et al., 1993), has been proposed as a universal standard for singlet oxygen studies (Oliveros et al., 1999). However, PNS is negatively charged, whereas positively charged PS are essential for good antimicrobial activity (Alves et al., 2009). Therefore, recently SAPYR [2-((4pyridinyl)methyl)-1H-phenalen-1-one chloride] was introduced as the lead compound of a batch of positively charged derivatives based on a 7-perinaphthenone-structure, eliminating the drawback of PNS, but conserving the high singlet oxygen quantum yield of $\Phi_{\Delta} 0.99$ (Cieplik et al., 2013b; Späth et al., 2014). Our group evaluated SAPYR for its anti-biofilm properties against Enterococcus faecalis and Actinomyces naeslundii grown in monospecies or in polyspecies biofilms consisting of Enterococcus faecalis, Actinomyces naeslundii, and Fusobacterium nucleatum (Cieplik et al., 2013b). These biofilms were cultured for $72 \mathrm{~h}$, afterwards incubated for $60 \mathrm{~min}$ with the respective PS at $100 \mu \mathrm{M}$ (TMPyP served as a reference PS) and irradiated for $120 \mathrm{~s}$ with a blue LED, usually applied for polymerization of dental resins (light intensity at sample-level: $600 \mathrm{~mW} / \mathrm{cm}^{2}$ ). This light source was used, as it is widely applied in dental practice, although its emission spectrum shows only partial overlap with the absorption spectra of SAPYR and TMPyP. Nevertheless, aPDT with SAPYR resulted in CFU-reductions of more than $5 \log _{10}$ for Enterococcus faecalis in both types of biofilm; Actinomyces naeslundii was inactivated by more than $2 \log _{10}$ in monospecies and by more than $4 \log _{10}$ in polyspecies biofilms. In contrast, as mentioned above (Section Porphyrins, Chlorins, and Phthalocyanines), TMPyP had no effect at all (Cieplik et al., 2013b).

As a completely distinct class of PS, fullerenes are ballshaped cage molecules composed of carbon atoms, whereby fullerene C60 has to be regarded as the most studied compound (Sharma et al., 2011). Recently, the group of Michael R. Hamblin introduced several functionalized cationic fullerenes as PS for aPDT, which showed notable results in vitro against planktonic bacteria and yeasts (Mizuno et al., 2011). These compounds absorb extensively in the visible and UV wavelength range (Sharma et al., 2011) and react-in contrast to perinaphthenone derivatives-predominantly according to type I mechanism, thus producing mainly superoxide (Mizuno et al., 2011). However, until now fullerenes have not been tested for their antimicrobial photodynamic efficacy against biofilms (Table 4).

\section{SYNOPSIS}

All above-mentioned studies have in common that they are difficult to compare with each other. In general, with respect to biofilm cultivation, different culture protocols with varying culture periods lead to different biofilms at distinct stages of development. This is a general problem, which has not been solved yet. While for testing a given antimicrobial against planktonic cultures, MIC (minimal inhibitory concentration), and $\mathrm{MBC}$ (minimal bactericidal concentration) assays are standardly used, protocols or assays for testing antimicrobials in biofilm models (e.g., the Calgary Biofilm Device described by Ceri et al., 1999) are not in widespread use. Consequently, the effect of a given PS on $24 \mathrm{~h}$ old biofilms described in one study can hardly be compared to the effect of the same PS on 4 weeks old biofilms described in another study. The ASM stated in 2010 that every new approach has to reach a $3 \log _{10}$ step reduction rate of CFU before being able to use the terms "antimicrobial" or "antibacterial," wherefore CFU assays are mandatory for testing PS for aPDT against biofilms. However, it has to be considered that it is a critical point to disaggregate bacteria from a biofilm before doing a classical CFU assay. Therefore, Live/Dead staining would be a suitable addon tool for confirmation of results. Live/Dead staining cannot be used as the only evaluation method, though, as it only yields relative fluorescence counts without making an exact quantification possible.

Another point is that in most studies, which deal with inactivation of biofilms, the presence of an EPS has not been experimentally verified (e.g., by fluorescence microscopy), althoughaccording to the general definition of a biofilm-this has to be regarded as a major criterium for using the term "biofim" (Donlan and Costerton, 2002). Consequently, in some cases the "biofilms" used may not be true biofilms, but rather attached bacteria without any EPS. Therefore, the robustness, reproducibility and relevance of the distinct biofilm assays, which were applied in the studies discussed above, remain debatable. In addition, it has to be considered that there is a remarkable difference between in vitro biofilms and biofilms formed in vivo on tooth or mucosal surfaces in the oral cavity. These clinical biofilms consist of hundreds of bacterial and fungal species obtaining a thickness of $1000 \mu \mathrm{m}$ at least (Teixeira et al., 2012), whereas under laboratory conditions it is not able to mimic such complex biofilms. Nevertheless, from the studies implied in this review it can be concluded that there are not necessarily differences in inactivation rates between bacterial and fungal biofilms or between monospecies and polyspecies biofilms. In contrast, as shown by Teixeira et al. and also by our group, the thickness of an in vitro biofilm and its amount of EPS affect the efficacy of photodynamic inactivation, which may be due to the inability of a PS to diffuse throughout the entire biofilm (Teixeira et al., 2012; Cieplik et al., 2013b).

From a photophysical point of view, it is also problematic to compare the efficacy of two distinct PS on identically cultured biofilms, as absorption characteristics may vary for every PS. Therefore, the overlaps of two distinct PS with the emission of the same light source, thus the absorbed energies, can differ vastly even if the applied energies are equivalent. For example, this was shown by our group for TMPyP and SAPYR, 
where the total absorbed energies were $12.5 \mathrm{~J}$ for SAPYR vs. $80 \mathrm{~J}$ for TMPyP, while the applied energies were matching (Cieplik et al., 2013b). Giving the example of MB and SAPYR, different light sources have to be used, as MB is activated by red light, whereas SAPYR absorbs in the blue spectral range. Consequently, it is not reasonable to directly compare efficacy rates, which were revealed for a given PS in studies published by different groups.

Furthermore, for evaluation of the antimicrobial properties of a given PS it is essential to include appropriate control groups in the experimental protocol. Typically, in so-called negative controls, samples are treated either with PS only (PS+L-) or with light only (PS-L+) or remain completely untreated (PS-L). In contrast, positive controls mean that the efficacy of aPDT with a respective PS is compared to that of a drug, which has already demonstrated to exhibit pronounced antimicrobial properties; in dentistry, suitable drugs for positive control groups would be $\mathrm{CHX}$ or $\mathrm{NaOCl}$. However, out of 22 studies reviewed in this paper, only one (Meire et al., 2012) used an antimicrobial drug $(\mathrm{NaOCl})$ as a positive control. However, in this study no reagent was used for stopping the activity of $\mathrm{NaOCl}$ after the respective immersion period (Meire et al., 2012). It has to be considered that the treatment periods of suchlike antimicrobials are difficult to restrict when no reagents for stopping their antimicrobial effect are used, whereas in contrast the effect of aPDT is stopped immediately when the light is turned off, which reduces comparability between these approaches. For example, Hecker et al. showed that treatment with $1.0 \%$ and $3.0 \% \mathrm{NaOCl}$ only had a biologically relevant effect ( $\left.\geq 3 \log _{10}\right)$ on planktonic Enterococcus faecalis, which was grown in artificially infected bovine root canals, when the antimicrobial action of $\mathrm{NaOCl}$ was not arrested by adding sodium thiosulfate after the respective treatment period $(30,60$, or 600 s). In contrast, when sodium thiosulfate was added, no biologically relevant effect $\left(\geq 3 \log _{10}\right)$ could be observed. Therefore, the authors concluded that blocking the antimicrobial effect of a given antimicrobial after the required treatment period is essential for laboratory testing in order to avoid distorting results due to a prolonged action of the respective drug (Hecker et al., 2013).

All in all, the findings reviewed in the present paper imply that aPDT is an effective approach for inactivation of biofilms formed in vitro. Concerning the situation in the oral cavity, these in vitro results are promising for an application of aPDT as a supportive antimicrobial tool to combat biofilm-associated infections in vivo. Oral infections such as periodontal, endodontic or mucosal infections, and more recently periimplantitis represent-beside dermal infections-a superior field for application of aPDT due to their localized nature. Nevertheless, until now clinical oral application of aPDT is still in its infancy; clinical studies on aPDT were mainly conducted with phenothiazinium derivatives like $\mathrm{MB}$ and TBO as PS examining the potential of the photodynamic approach as a supportive tool for treatment of periodontitis, periimplantitis, or endodontic infection, whereby the results of these studies are quite conflicting (Gursoy et al., 2013). Moreover, using these PS, the patients' aesthetic may get compromised due to the strong blue color of these PS. For example, in periodontal application the oral soft tissues may get stained bluish for at least a few hours after treatment (Hayek et al., 2005; Sorkhdini et al., 2013). When used in endodontics, even persistent blue staining of dental structure via diffusion of the PS into dentinal tubules may get induced, by what a further decoloration step using appropriate chemical compounds may get necessary (Carvalho et al., 2011). Although there is current research on developing only slightly or even tooth-like colored PS, e.g., perinaphthenone derivatives like SAPYR (Cieplik et al., 2013b; Späth et al., 2014), further clinical research is needed-particularly on these new PS-for employing aPDT regularly in dental practice.

\section{ACKNOWLEDGMENTS}

Isabelle Tabenski is thanked for helpful discussions. Andreas Späth is gratefully acknowledged for his advice regarding chemical issues. This work was supported by the German Research Foundation (DFG) within the funding programme Open Access Publishing.

\section{REFERENCES}

Aggarwal, B. B., Sundaram, C., Malani, N., and Ichikawa, H. (2007). Curcumin: the Indian solid gold. Adv. Exp. Med. Biol. 595, 1-75. doi: 10.1007/978-0-38746401-5_1

Al-Ahmad, A., Ameen, H., Pelz, K., Karygianni, L., Wittmer, A., Anderson, A. C., et al. (2014). Antibiotic resistance and capacity for biofilm formation of different bacteria isolated from endodontic infections associated with root-filled teeth. J. Endod. 40, 223-230. doi: 10.1016/j.joen.2013.07.023

Alves, E., Costa, L., Carvalho, C. M., Tomé, J. P., Faustino, M. A., Neves, M. G., et al. (2009). Charge effect on the photoinactivation of Gram-negative and Grampositive bacteria by cationic meso-substituted porphyrins. BMC Microbiol. 9:70. doi: 10.1186/1471-2180-9-70

Alves, E., Faustino, M. A., Neves, M. G., Cunha, A., Tome, J., and Almeida, A. (2014). An insight on bacterial cellular targets of photodynamic inactivation. Future Med. Chem. 6, 141-164. doi: 10.4155/fmc.13.211

Araújo, N. C., Fontana, C. R., Bagnato, V. S., and Gerbi, M. E. M. (2012). Photodynamic effects of curcumin against cariogenic pathogens. Photomed. Laser Surg. 30, 393-399. doi: 10.1089/pho.2011.3195

Araújo, N. C., Fontana, C. R., Bagnato, V. S., and Gerbi, M. E. M. (2014). Photodynamic antimicrobial therapy of curcumin in biofilms and carious dentine. Lasers Med. Sci. 29, 629-635. doi: 10.1007/s10103-013-1369-3

Arias, C. A., and Murray, B. E. (2009). Antibiotic-resistant bugs in the 21st century-a clinical super-challenge. N. Engl. J. Med. 360, 439-443. doi: 10.1056/NEJMp0804651

Boles, B. R., Thoendel, M., and Singh, P. K. (2004). Self-generated diversity produces "insurance effects" in biofilm communities. Proc. Natl. Acad. Sci. U.S.A. 101, 16630-16635. doi: 10.1073/pnas.0407460101

Caro, H. (1878). Improvement in the Production of Dye-Stuffs from Methyl-Aniline. Patent No. 204,796. Mannheim: U.S. Patent Office.

Carvalho, E. D. S., Mello, I., Albergaria, S. J., Habitante, S. M., Lage-Marques, J. L., and Raldi, D. P. (2011). Effect of chemical substances in removing methylene blue after photodynamic therapy in root canal treatment. Photomed. Laser Surg. 29, 559-563. doi: 10.1089/pho.2010.2922

Ceri, H., Olson, M. E., Stremick, C., Read, R. R., Morck, D., and Buret, A. (1999). The Calgary Biofilm Device: new technology for rapid determination of antibiotic susceptibilities of bacterial biofilms. J. Clin. Microbiol. 37, 1771-1776.

Cieplik, F., Späth, A., Leibl, C., Gollmer, A., Regensburger, J., Tabenski, L., et al. (2013a). Blue light kills Aggregatibacter actinomycetemcomitans due to its endogenous photosensitizers. Clin. Oral Investig. doi: 10.1007/s00784-0131151-8. [Epub ahead of print].

Cieplik, F., Späth, A., Regensburger, J., Gollmer, A., Tabenski, L., Hiller, K.A., et al. (2013b). Photodynamic biofilm inactivation by SAPYR-An exclusive singlet oxygen photosensitizer. Free Radic. Biol. Med. 65, 477-487. doi: 10.1016/j.freeradbiomed.2013.07.031

Collins, T. L., Markus, E. A., Hassett, D. J., and Robinson, J. B. (2010). The effect of a cationic porphyrin on Pseudomonas aeruginosa biofilms. Curr. Microbiol. 61, 411-416. doi: 10.1007/s00284-010-9629-y 
Crivello, J. V., and Bulut, U. (2005). Curcumin: a naturally occurring longwavelength photosensitizer for diaryliodonium salts. J. Polym. Sci. A Polym. Chem. 43, 5217-5231. doi: 10.1002/pola.21017

Dahl, T. A., McGowan, W. M., Shand, M. A., and Srinivasan, V. S. (1989). Photokilling of bacteria by the natural dye curcumin. Arch. Microbiol. 151, 183-185.

DeRosa, M. C., and Crutchley, R. J. (2002). Photosensitized singlet oxygen and its applications. Coord. Chem. Rev. 233-234, 351-371. doi: 10.1016/S00108545(02)00034-6

Di Poto, A., Sbarra, M. S., Provenza, G., Visai, L., and Speziale, P. (2009). The effect of photodynamic treatment combined with antibiotic action or host defence mechanisms on Staphylococcus aureus biofilms. Biomaterials 30, 3158-3166. doi: 10.1016/j.biomaterials.2009.02.038

Donlan, R. M., and Costerton, J. W. (2002). Biofilms: survival mechanisms of clinically relevant microorganisms. Clin. Microbiol. Rev. 15, 167-193. doi: 10.1128/CMR.15.2.167-193.2002

Dovigo, L. N., Carmello, J. C., Carvalho, M. T., Mima, E. G., Vergani, C. E., Bagnato, V. S., et al. (2013). Photodynamic inactivation of clinical isolates of Candida using Photodithazine ${ }^{\circledR}$. Biofouling 29, 1057-1067. doi: 10.1080/08927014.2013.827668

Eichner, A., Gonzales, F. P., Felgenträger, A., Regensburger, J., Holzmann, T., Schneider-Brachert, W., et al. (2013). Dirty hands: photodynamic killing of human pathogens like EHEC, MRSA and Candida within seconds. Photochem. Photobiol. Sci. 12, 135-147. doi: 10.1039/c2pp25164g

Felgenträger, A., Maisch, T., Dobler, D., and Späth, A. (2013). Hydrogen bond acceptors and additional cationic charges in methylene blue derivatives: photophysics and antimicrobial efficiency. Biomed Res. Int. 2013:482167. doi: $10.1155 / 2013 / 482167$

Fernandez, J. M., Bilgin, M. D., and Grossweiner, L. I. (1997). Singlet oxygen generation by photodynamic agents. J. Photochem. Photobiol. B Biol. 37, 131-140. doi: 10.1016/S1011-1344(96)07349-6

Fimple, J. L., Fontana, C. R., Foschi, F., Ruggiero, K., Song, X., Pagonis, T. C., et al. (2008). Photodynamic treatment of endodontic polymicrobial infection in vitro. J Endod 34, 728-734. doi: 10.1016/j.joen.2008.03.011

Fontana, C. R., Abernethy, A. D., Som, S., Ruggiero, K., Doucette, S., Marcantonio, R. C., et al. (2009). The antibacterial effect of photodynamic therapy in dental plaque-derived biofilms. J. Periodont. Res. 44, 751-759. doi: 10.1111/j.16000765.2008.01187.x

Freire, F., Costa, A. C. B. P., Pereira, C. A., Beltrame Junior, M., Junqueira, J. C., and Jorge, A. O. C. (2013). Comparison of the effect of rose bengal- and eosin Y-mediated photodynamic inactivation on planktonic cells and biofilms of Candida albicans. Lasers Med. Sci. 1-7. doi: 10.1007/s10103-013-1435-x

Gonzales, F. P., Felgenträger, A., Bäumler, W., and Maisch, T. (2013). Fungicidal photodynamic effect of a twofold positively charged porphyrin against Candida albicans planktonic cells and biofilms. Future Microbiol. 8, 785-797. doi: $10.2217 / \mathrm{fmb} .13 .44$

Gouterman, M. (1961). Spectra of porphyrins. J. Mol. Spectrosc. 8, 138-163. doi: 10.1016/0022-2852(61)90236-3

Grinholc, M. (2014). Comments on "Biofilms of Candida albicans serotypes A and B differ in their sensitivity to photodynamic therapy." Lasers Med Sci. doi: 10.1007/s10103-014-1591-7. [Epub ahead of print].

Gursoy, H., Ozcakir-Tomruk, C., Tanalp, J., and Yilmaz, S. (2013). Photodynamic therapy in dentistry: a literature review. Clin. Oral Investig. 17, 1113-1125. doi: 10.1007/s00784-012-0845-7

Hayek, R. R. A., Araújo, N. S., Gioso, M. A., Ferreira, J., Baptista-Sobrinho, C. A., Yamada, A. M., et al. (2005). Comparative study between the effects of photodynamic therapy and conventional therapy on microbial reduction in ligature-induced peri-implantitis in dogs. J. Periodontol. 76, 1275-1281. doi: 10.1902/jop.2005.76.8.1275

Hecker, S., Hiller, K.-A., Galler, K. M., Erb, S., Mader, T., and Schmalz, G. (2013). Establishment of an optimized ex vivo system for artificial root canal infection evaluated by use of sodium hypochlorite and the photodynamic therapy. Int. Endod. J. 46, 449-457. doi: 10.1111/iej.12010

Kishen, A., Upadya, M., Tegos, G. P., and Hamblin, M. R. (2010). Efflux pump inhibitor potentiates antimicrobial photodynamic inactivation of Enterococcus faecalis biofilm. Photochem. Photobiol. 86, 1343-1349. doi: 10.1111/j.17511097.2010.00792.x

Kolter, R., and Greenberg, E. P. (2006). Microbial sciences: the superficial life of microbes. Nature 441, 300-302. doi: 10.1038/441300a
König, K., Teschke, M., Sigusch, B., Glockmann, E., Eick, S., and Pfister, W. (2000). Red light kills bacteria via photodynamic action. Cell. Mol. Biol. 46, 1297-1303.

Lennon, A. M., Buchalla, W., Brune, L., Zimmermann, O., Gross, U., and Attin, T. (2006). The ability of selected oral microorganisms to emit red fluorescence. Caries Res. 40, 2-5. doi: 10.1159/000088898

Leung, E., Weil, D. E., Raviglione, M., Nakatani, H., and World Health Organization World Health Day Antimicrobial Resistance Technical Working, Group. (2011). The WHO policy package to combat antimicrobial resistance. Bull. World Health Organ. 89, 390-392. doi: 10.2471/BLT.11.088435

Lewis, K. (2007). Persister cells, dormancy and infectious disease. Nat. Rev. Microbiol. 5, 48-56. doi: 10.1038/nrmicro 1557

Lo, A. W., Seers, C. A., Boyce, J. D., Dashper, S. G., Slakeski, N., Lissel, J. P., et al. (2009). Comparative transcriptomic analysis of Porphyromonas gingivalis biofilm and planktonic cells. BMC Microbiol. 9:18. doi: 10.1186/1471-2180-9-18

López-Muñoz, F., Alamo, C., Cuenca, E., Shen, W. W., Clervoy, P., and Rubio, G. (2005). History of the discovery and clinical introduction of chlorpromazine. Ann. Clin. Psychiatry 17, 113-135. doi: 10.3109/10401230591002002

Mah, T.-F. C., and O'Toole, G. A. (2001). Mechanisms of biofilm resistance to antimicrobial agents. Trends Microbiol. 9, 34-39. doi: 10.1016/S0966842X(00)01913-2

Maisch, T., Baier, J., Franz, B., Maier, M., Landthaler, M., Szeimies, R.-M., et al. (2007). The role of singlet oxygen and oxygen concentration in photodynamic inactivation of bacteria. Proc. Natl. Acad. Sci. U.S.A. 104, 7223-7228. doi: 10.1073/pnas.0611328104

Maisch, T., Hackbarth, S., Regensburger, J., Felgenträger, A., Bäumler, W., Landthaler, M., et al. (2011). Photodynamic inactivation of multi-resistant bacteria (PIB) - a new approach to treat superficial infections in the 21 st century. J. Dtsch. Dermatol. Ges. 9, 360-366. doi: 10.1111/j.1610-0387.2010.07577.x

Maisch, T., Spannberger, F., Regensburger, J., Felgenträger, A., and Bäumler, W. (2012). Fast and effective: intense pulse light photodynamic inactivation of bacteria. J. Ind. Microbiol. Biotechnol. 39, 1013-1021. doi: 10.1007/s10295-0121103-3

Maisch, T., Szeimies, R.-M., Jori, G., and Abels, C. (2004). Antibacterial photodynamic therapy in dermatology. Photochem. Photobiol. Sci. 3, 907-917. doi: $10.1039 / \mathrm{b} 407622 \mathrm{~b}$

Meire, M. A., Coenye, T., Nelis, H. J., and De Moor, R. J. G. (2012). Evaluation of Nd:YAG and Er:YAG irradiation, antibacterial photodynamic therapy and sodium hypochlorite treatment on Enterococcus faecalis biofilms. Int. Endod. J. 45, 482-491. doi: 10.1111/j.1365-2591.2011.02000.x

Metcalf, D., Robinson, C., Devine, D., and Wood, S. (2006). Enhancement of erythrosine-mediated photodynamic therapy of Streptococcus mutans biofilms by light fractionation. J. Antimicrob. Chemother. 58, 190-192. doi: 10.1093/jac/dkl205

Mizuno, K., Zhiyentayev, T., Huang, L., Khalil, S., Nasim, F., Tegos, G. P., et al. (2011). Antimicrobial photodynamic therapy with functionalized fullerenes: quantitative structure-activity relationships. J. Nanomed. Nanotechnol. 2, 1-9. doi: 10.4172/2157-7439.1000109

Nonell, S., Gonzalez, M., and Trull, F. R. (1993). 1H-Phenalen-1-one-2-sulfonic acid: an extremely efficient singlet molecular oxygen sensitizer for aqueous media. Afinidad 50, 445-450. doi: 10.1039/b810413a

Oliveros, E., Bossmann, S. H., Nonell, S., and Martí, C. (1999). Photochemistry of the singlet oxygen $\left[\mathrm{O}_{2}\left({ }^{1} \Delta_{g}\right)\right]$ sensitizer perinaphthenone (phenalenone) in $\mathrm{N}, \mathrm{N}^{\prime}$-dimethylacetamide and 1,4-dioxane. New J. Chem. 23, 85-93. doi: 10.1039/A804054K

PA-07-288: Immunology of Biofilms (R01). grants1.nih.gov. Available online at: http://grants1.nih.gov/grants/guide/pa-files/PA-07-288.html (Accessed January 14, 2014).

Pereira, C. A., Costa, A. C. B. P., Carreira, C. M., Junqueira, J. C., and Jorge, A. O. C. (2013). Photodynamic inactivation of Streptococcus mutans and Streptococcus sanguinis biofilms in vitro. Lasers Med. Sci. 28, 859-864. doi: 10.1007/s10103012-1175-3

Prates, R. A., Kato, I. T., Ribeiro, M. S., Tegos, G. P., and Hamblin, M. R. (2011). Influence of multidrug efflux systems on methylene blue-mediated photodynamic inactivation of Candida albicans. J. Antimicrob. Chemother. 66, 1525-1532. doi: 10.1093/jac/dkr160

Quishida, C. C. C., Carmello, J. C., Mima, E. G., de, O., Bagnato, V. S., Machado, A. L., et al. (2013). Susceptibility of multispecies biofilm to photodynamic therapy using Photodithazine ${ }^{\circledR}$. Lasers Med. Sci. doi: 10.1007/s10103-013-1397-z. [Epub ahead of print]. 
Rams, T. E., Degener, J. E., and Winkelhoff, A. J. (2014). Antibiotic resistance in human chronic periodontitis microbiota. J. Periodontol. 85, 160-169. doi: 10.1902/jop.2013.130142

Ribeiro, A. P. D., Andrade, M. C., Bagnato, V. S., Vergani, C. E., Primo, F. L., Tedesco, A. C., et al. (2013a). Antimicrobial photodynamic therapy against pathogenic bacterial suspensions and biofilms using chloro-aluminum phthalocyanine encapsulated in nanoemulsions. Lasers Med. Sci. doi: 10.1007/s10103013-1354-x. [Epub ahead of print].

Ribeiro, A. P. D., Andrade, M. C., da Silva, J., de, F., Jorge, J. H., Primo, F. L., et al. (2013b). Photodynamic inactivation of planktonic cultures and biofilms of Candida albicans mediated by aluminum-chloride-phthalocyanine entrapped in nanoemulsions. Photochem. Photobiol. 89, 111-119. doi: 10.1111/j.17511097.2012.01198.x

Rossolini, G. M., and Mantengoli, E. (2008). Antimicrobial resistance in Europe and its potential impact on empirical therapy. Clin. Microbiol. Infect. 14(Suppl. 6), 2-8. doi: 10.1111/j.1469-0691.2008.02126.x

Rossoni, R. D., Barbosa, J. O., de Oliveira, F. E., de Oliveira, L. D., Jorge, A. O. C., and Junqueira, J. C. (2014). Biofilms of Candida albicans serotypes A and B differ in their sensitivity to photodynamic therapy. Lasers Med. Sci. doi: 10.1007/s10103-014-1570-z. [Epub ahead of print].

Schweitzer, C., and Schmidt, R. (2003). Physical mechanisms of generation and deactivation of singlet oxygen. Chem. Rev. 103, 1685-1757. doi: $10.1021 / \mathrm{cr} 010371 \mathrm{~d}$

Shani, S., Friedman, M., and Steinberg, D. (2000). The anticariogenic effect of amine fluorides on Streptococcus sobrinus and glucosyltransferase in biofilms. Caries Res. 34, 260-267. doi: 10.1159/000016600

Sharma, S. K., Dai, T., Kharkwal, G. B., Huang, Y.-Y., Huang, L., De Arce, V. J. B., et al. (2011). Drug discovery of antimicrobial photosensitizers using animal models. Curr. Pharm. Des. 17, 1303-1319. doi: 10.2174/1381612117957 03735

Shemesh, M., Tam, A., and Steinberg, D. (2007). Differential gene expression profiling of Streptococcus mutans cultured under biofilm and planktonic conditions. Microbiology 153, 1307-1317. doi: 10.1099/mic.0.2006/002030-0

Shrestha, A., Hamblin, M. R., and Kishen, A. (2012). Characterization of a conjugate between Rose Bengal and chitosan for targeted antibiofilm and tissue stabilization effects as a potential treatment of infected dentin. Antimicrob. Agents Chemother. 56, 4876-4884. doi: 10.1128/AAC.00810-12

Shrestha, A., and Kishen, A. (2012). Polycationic chitosan-conjugated photosensitizer for antibacterial photodynamic therapy. Photochem. Photobiol. 88, 577-583. doi: 10.1111/j.1751-1097.2011.01026.x

Sorkhdini, P., Moslemi, N., Jamshidi, S., Jamali, R., Amirzargar, A. A., and Fekrazad, R. (2013). Effect of hydrosoluble chlorine-mediated antimicrobial photodynamic therapy on clinical parameters and cytokine profile in ligature-induced periodontitis in dogs. J. Periodontol. 84, 793-800. doi: 10.1902/jop.2012.120330

Soukos, N. S., and Goodson, J. M. (2011). Photodynamic therapy in the control of oral biofilms. Periodontol. 2000 55, 143-166. doi: 10.1111/j.16000757.2010.00346.x

Soukos, N. S., Som, S., Abernethy, A. D., Ruggiero, K., Dunham, J., Lee, C., et al. (2005). Phototargeting oral black-pigmented bacteria. Antimicrob. Agents Chemother. 49, 1391-1396. doi: 10.1128/AAC.49.4.1391-1396.2005

Späth, A., Leibl, C., Cieplik, F., Lehner, K., Regensburger, J., Hiller, K.-A., et al. (2014). Improving photodynamic inactivation of bacteria in dentistry: highly effective and fast killing of oral key pathogens with novel tooth-colored type-II photosensitizers. J. Med. Chem. 57, 5157-5168. doi: 10.1021/jm4019492

Stewart, P. S., and Costerton, J. W. (2001). Antibiotic resistance of bacteria in biofilms. Lancet 358, 135-138. doi: 10.1016/S0140-6736(01)05321-1

Svensäter, G., Welin, J., Wilkins, J. C., Beighton, D., and Hamilton, I. R. (2001). Protein expression by planktonic and biofilm cells of Streptococcus mutans. FEMS Microbiol. Lett. 205, 139-146. doi: 10.1111/j.1574-6968.2001. tb10937.x
Tegos, G. P., and Hamblin, M. R. (2006). Phenothiazinium antimicrobial photosensitizers are substrates of bacterial multidrug resistance pumps. Antimicrob. Agents Chemother. 50, 196-203. doi: 10.1128/AAC.50.1.196-203.2006

Tegos, G. P., Masago, K., Aziz, F., Higginbotham, A., Stermitz, F. R., and Hamblin, M. R. (2008). Inhibitors of bacterial multidrug efflux pumps potentiate antimicrobial photoinactivation. Antimicrob. Agents Chemother. 52, 3202-3209. doi: 10.1128/AAC.00006-08

Teixeira, A. H., Pereira, E. S., Rodrigues, L. K. A., Saxena, D., Duarte, S., and Zanin, I. C. J. (2012). Effect of photodynamic antimicrobial chemotherapy on in vitro and in situ biofilms. Caries Res. 46, 549-554. doi: 10.1159/000341190

Voos, A. C., Kranz, S., Tonndorf Martini, S., Voelpel, A., Sigusch, H., Staudte, H., et al. (2014). Photodynamic antimicrobial effect of safranine $\mathrm{O}$ on an ex vivo periodontal biofilm. Lasers Surg. Med. 46, 235-243. doi: 10.1002/lsm.22217

Wainwright, M. (1998). Photodynamic antimicrobial chemotherapy (PACT). J. Antimicrob. Chemother. 42, 13-28. doi: 10.1093/jac/42.1.13

Welin, J., Wilkins, J. C., Beighton, D., and Svensäter, G. (2004). Protein expression by Streptococcus mutans during initial stage of biofilm formation. Appl. Environ. Microbiol. 70, 3736-3741. doi: 10.1128/AEM.70.6.3736-3741.2004

Wilkinson, F., Helman, W. P., and Ross, A. B. (1993). Quantum yields for the photosensitized formation of the lowest electronically excited singlet state of molecular oxygen in solution. J. Phys. Chem. Ref. Data 22, 113-262. doi: $10.1063 / 1.555934$

Wood, S., Metcalf, D., Devine, D., and Robinson, C. (2006). Erythrosine is a potential photosensitizer for the photodynamic therapy of oral plaque biofilms. J. Antimicrob. Chemother. 57, 680-684. doi: 10.1093/jac/dkl021

Yamamoto, T., Tamura, Y., and Yokota, T. (1988). Antiseptic and antibiotic resistance plasmid in Staphylococcus aureus that possesses ability to confer chlorhexidine and acrinol resistance. Antimicrob. Agents Chemother. 32, 932-935.

Yazdankhah, S. P., Scheie, A. A., Høiby, E. A., Lunestad, B.-T., Heir, E., Fotland, T. $\varnothing$., et al. (2006). Triclosan and antimicrobial resistance in bacteria: an overview. Microb. Drug Resist. 12, 83-90. doi: 10.1089/mdr.2006.12.83

Zand, V., Milani, A. S., Amini, M., Barhaghi, M. H. S., Lotfi, M., Rikhtegaran, S., et al. (2014). Antimicrobial efficacy of photodynamic therapy and sodium hypochlorite on monoculture biofilms of Enterococcus faecalis at different stages of development. Photomed. Laser Surg. 32, 245-251. doi: 10.1089/pho.2013.3557

Zanin, I. C. J., Gonçalves, R. B., Junior, A. B., Hope, C. K., and Pratten, J. (2005). Susceptibility of Streptococcus mutans biofilms to photodynamic therapy: an in vitro study. J. Antimicrob. Chemother. 56, 324-330. doi: 10.1093/jac/ dki232

Zanin, I. C. J., Lobo, M. M., Rodrigues, L. K. A., Pimenta, L. A. F., Höfling, J. F., and Gonçalves, R. B. (2006). Photosensitization of in vitro biofilms by toluidine blue O combined with a light-emitting diode. Eur. J. Oral Sci. 114, 64-69. doi: 10.1111/j.1600-0722.2006.00263.x

Conflict of Interest Statement: The authors declare that the research was conducted in the absence of any commercial or financial relationships that could be construed as a potential conflict of interest.

Received: 06 May 2014; accepted: 18 July 2014; published online: 12 August 2014. Citation: Cieplik F, Tabenski L, Buchalla W and Maisch T (2014) Antimicrobial photodynamic therapy for inactivation of biofilms formed by oral key pathogens. Front. Microbiol. 5:405. doi: 10.3389/fmicb.2014.00405

This article was submitted to Antimicrobials, Resistance and Chemotherapy, a section of the journal Frontiers in Microbiology.

Copyright (c) 2014 Cieplik, Tabenski, Buchalla and Maisch. This is an open-access article distributed under the terms of the Creative Commons Attribution License (CC BY). The use, distribution or reproduction in other forums is permitted, provided the original author(s) or licensor are credited and that the original publication in this journal is cited, in accordance with accepted academic practice. No use, distribution or reproduction is permitted which does not comply with these terms. 